
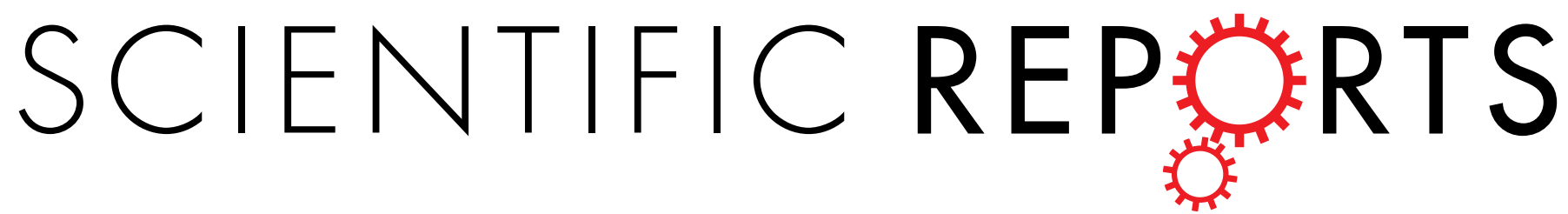

\title{
OPEN An oligo-His-tag of a targeting module does not influence its biodistribution and the retargeting capabilities of UniCAR T cells
}

Received: 24 January 2019

Accepted: 18 April 2019

Published online: 22 July 2019

\begin{abstract}
Justyna Jureczek ${ }^{1,2}$, Ralf Bergmann $\mathbb{1}^{3}$, Nicole Berndt ${ }^{1,3}$, Stefanie Koristka ${ }^{3}$, Alexandra Kegler ${ }^{3}$, Edinson Puentes-Cala ${ }^{4}$, Javier Andrés Soto ${ }^{5}$, Claudia Arndt ${ }^{3}$, Michael Bachmann ${ }^{1,2,3,6}$ \& Anja Feldmann ${ }^{3}$
\end{abstract}

Recently, we established the controllable modular UniCAR platform technology to advance the efficacy and safety of CART cell therapy. The UniCAR system is composed of (i) target modules (TMs) and (ii) UniCAR armed T cells. TMs are bispecific molecules that are able to bind to the tumor cell surface and simultaneously to UniCAR T cells. For interaction with UniCAR T cells, TMs contain a peptide epitope sequence which is recognised by UniCART cells. So far, a series of TMs against a variety of tumor targets including against the prostate stem cell antigen (PSCA) were constructed and functionally characterised. In order to facilitate their purification all these TMs are expressed as recombinant proteins equipped with an oligo-His-tag. The aim of the here presented manuscript was to learn whether or not the oligo-His-tag of the TM influences the UniCAR system. For this purpose, we constructed TMs against PSCA equipped with or lacking an oligo-His-tag. Both TMs were compared side by side including for functionality and biodistribution. According to our data, an oligo-His-tag of a UniCAR TM has only little if any effect on its binding affinity, in vitro and in vivo killing capability and in vivo biodistribution.

Chimeric antigen receptors (CARs) are synthetic receptors comprising an antigen recognition domain, mostly fused to the signalling domain of the $\mathrm{CD} 3 \zeta$ chain with one or more co-stimulatory domain $(s)^{1-4}$. CAR engineered immune cells can target surface antigens independently of MHC expression. While impressive clinical responses were reported in patients with hematological malignancies ${ }^{5-15}$, several obstacles prevent the broader application of the CAR technology especially for solid tumors. For instance, the expression of most if not all tumor-associated antigens (TAAs) is not limited to tumor cells. Varying levels of TAAs are also found on non-malignant cells of vital tissues. In order to increase the safety of the CAR technology and to minimise on-target/off-tumor toxicities but also other potentially life-threatening side effects, such as tumor lysis syndrome and cytokine release syndrome, a series of strategies have been developed including for example the use of suicide genes, the CRISPR/ Cas9 system, targeting of co-expressed surface antigens, or gated targeting strategies ${ }^{16-21}$.

An alternative way to control the activity of artificial receptors is the imitation of natural ligand/receptor systems. Already in 2012, Urbanska et al. described such an artificial receptor system based on chicken avidin as artificial extracellular receptor domain instead of an anti-TAA antibody domain of a CAR ${ }^{22}$. T cells modified with such artificial avidin receptors are inactive but can interact with target cells via biotinylated adaptor molecules e.g. biotinylated antibodies ${ }^{22,23}$. However, the antigenicity of chicken avidin or bacterial streptavidin and the presence of natural anti-biotin antibodies in sera of healthy individuals ${ }^{24}$ might limit the use of such receptors in humans. To overcome such limitations we described in 2014 a modular CAR system termed UniCAR system ${ }^{25}$. Since then

${ }^{1}$ German Cancer Consortium (DKTK), partner site Dresden and German Cancer Research Center (DKFZ), Heidelberg, Germany. ${ }^{2}$ University Cancer Center (UCC), Tumor Immunology, University Hospital Carl Gustav Carus, TU Dresden, Dresden, Germany. ${ }^{3}$ Institute of Radiopharmaceutical Cancer Research, Helmholtz-Zentrum Dresden-Rossendorf (HZDR), Dresden, Germany. ${ }^{4}$ Corporación para la Investigación de la Corrosión (CIC), Piedecuesta, Colombia. ${ }^{5}$ Universidad de Santander, Cúcuta, Colombia. ${ }^{6}$ National Center for Tumor Diseases (NCT), University Hospital Carl Gustav Carus, TU Dresden, Dresden, Germany. Correspondence and requests for materials should be addressed to M.B. (email: m.bachmann@hzdr.de) 
A

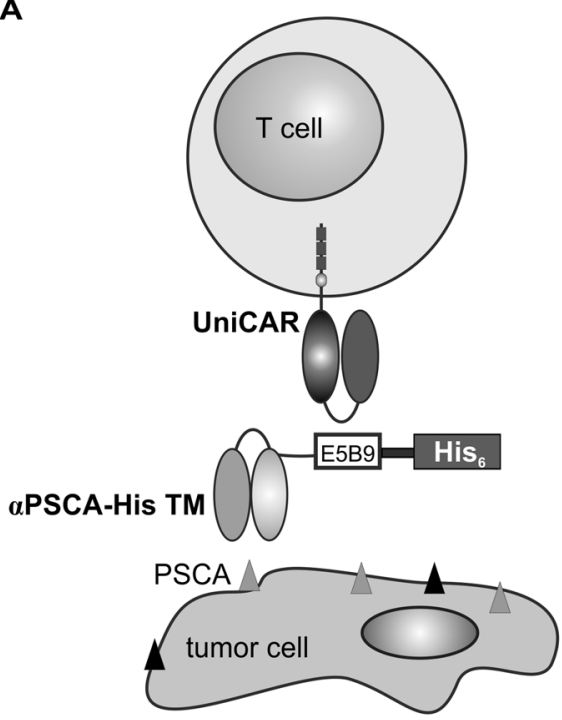

B

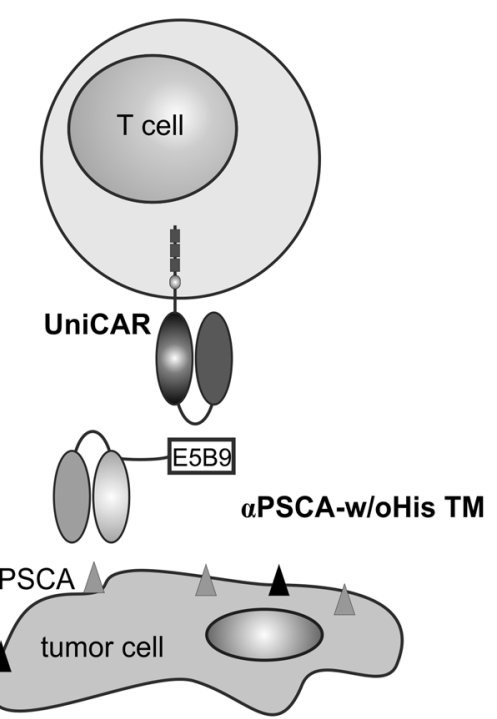

Figure 1. Schematic representation of the UniCAR system. The UniCAR system consists of two components: (i) T cells genetically modified with a universal chimeric antigen receptor (UniCAR) which is directed to the peptide epitope E5B9 (UniCAR epitope, E5B9) and (ii) a target module (TM). TMs are bifunctional molecules. Every TM contains the UniCAR epitope sequence E5B9. In addition to the UniCAR epitope a TM contains a binding domain which allows the TM to interact with a tumor-associated antigen on the cell surface of the target cell. Consequently, UniCAR T cells and TMs can form an immune complex. Moreover, the crosslinkage between UniCAR T cells and tumor cells leads to an activation of the UniCAR T cells and finally to the elimination of the tumor cells. UniCAR armed T cells are only switched on, when the TM is available, but automatically switched off when the TM is eliminated. Here we compare an $\alpha$ PSCA TM tagged with an oligo-

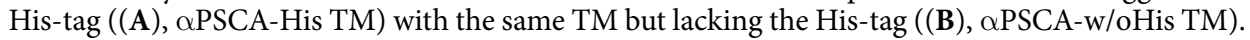

comparable switchable CAR strategies (e.g. sCARs) were described ${ }^{26-28}$. Like in conventional CARs the extracellular domain of UniCARs consists of an antibody domain. However, instead of a TAA, UniCARs recognise the human peptide sequence E5B9 (UniCAR epitope) that is part of the human nuclear autoantigen La/SS-B which is not present on living cells ${ }^{29}$. In contrast to the yeast peptide sequence used in $\mathrm{SCARs}^{28}$, the UniCAR epitope is proven even not to be immunogenic in patients suffering from autoimmune diseases and known to develop an immune response against the autoantigen La/SS-B. Moreover, even in case of an unexpected autoimmune response against $\mathrm{La}$, anti-La autoantibodies have been described to be protective against anti-DNA autoantibodies. After adoptive transfer into patients UniCAR T cells remain inert until cross-linking to target cells. For cross-linkage of UniCAR T cells to a tumor cell, a bispecific adaptor molecule is required which we termed target module (TM). Consequently, the TM determines the specificity. Until now, we have proven in vitro and in experimental mice that UniCAR T cells can be retargeted to a broad spectrum of targets including for example to CD19, CD123, CD33, PSCA, PSMA, GD2, EGFR, and STn ${ }^{30-36}$.

The majority of UniCAR TMs are based on antibody domains. To facilitate their purification an oligo-His-tag (His-tag) is usually fused to the C-terminus. So far it is unclear whether or not the presence of this His-tag can affect the UniCAR system. Therefore, we decided to construct TMs with (His-tagged TM) or without (un-tagged) a His-tag and compared their functional and kinetic properties. For comparative analysis the well characterised prostate stem cell antigen (PSCA)-specific TM was used here, which can effectively redirect UniCAR T cells to tumor cells presenting PSCA ${ }^{32}$.

\section{Results}

As summarised in the introduction section, the major aim of the presented work was to learn whether or not the presence of an oligo-His-tag in a UniCAR TM has an effect on the UniCAR system. The principle idea of the UniCAR system is schematically summarised in Fig. 1.

In order to enzymatically remove the oligo-His-tag, we (i) cloned a TM containing a recognition site for Tobacco Etch Virus (TEV) protease. The cleavage site was located upstream of the myc- and the oligo-His-tag but downstream of the UniCAR epitope E5B9. (ii) We established a cell line secreting this TM into cell culture supernatant. (iii) We isolated the TM from the cell culture supernatant via its His-tag using Nickel NTA affinity chromatography. (iv) After isolation we removed the His-tag via TEV protease cleavage and (v) separated the TM lacking the His-tag again via Nickel NTA affinity chromatography. (vi) We characterised the resulting un-tagged TM biochemically, (vii) analysed its functionality in vitro and in vivo, and finally (viii) compared its biochemical, functional properties as well as its biodistribution with the original His-tagged TM.

Construction and production of the His-tagged and un-tagged TMs. We previously described the development and functionality of a PSCA-specific TM that is able to redirect UniCAR T cells to PSCA-positive 

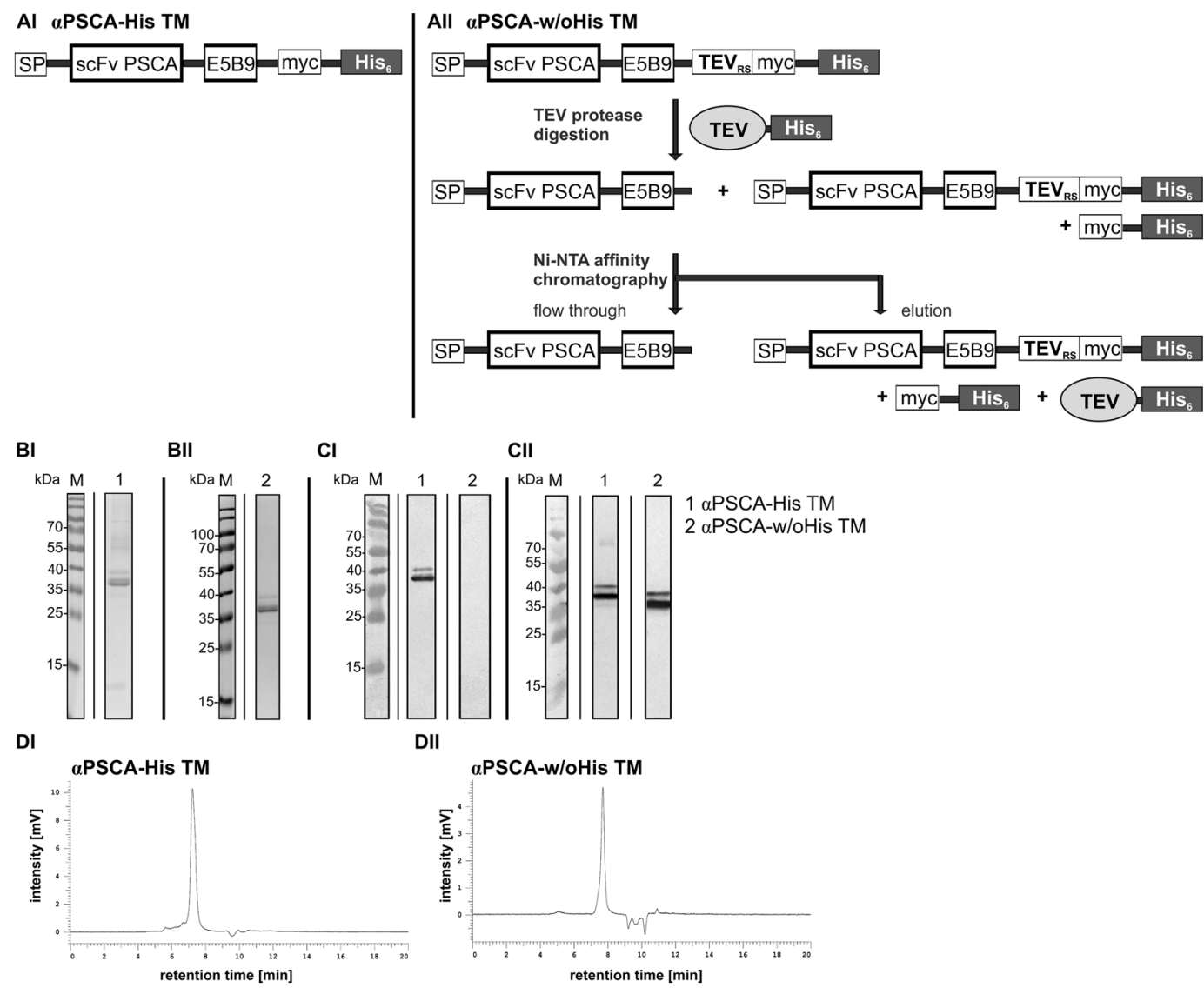

CII
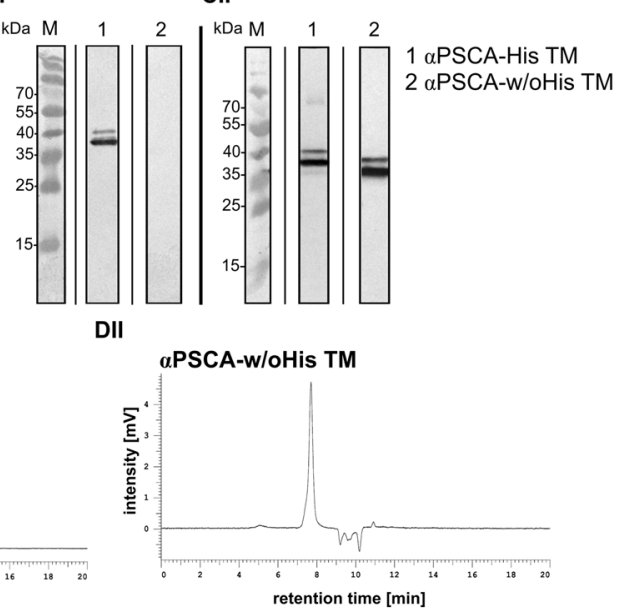

Figure 2. Design and purification of the $\alpha$ PSCA-His TM and the $\alpha$ PSCA-w/oHis TM. The previously described $\alpha$ PSCA-His TM that consists of the single-chain variable fragment (scFv) of the $\alpha$ PSCA mAb (MB1) and the E5B9 epitope for UniCAR recognition. (AI) In addition, the $\alpha$ PSCA-His TM is equipped with a mycand a hexahistidine $\left(\mathrm{His}_{6}\right)$-tag for purification via Ni-NTA affinity chromatography. The secretion of the TM into cell culture supernatant is mediated by the $\mathrm{N}$-terminal Ig kappa signal peptide sequence (SP). In contrast, the $\alpha$ PSCA-w/oHis TM was obtained in several steps. In order to remove the myc- and His-tag we introduced a TEV protease recognition site $\left(\mathrm{TEV}_{\mathrm{RS}}\right) \mathrm{N}$-terminally from the myc-tag and C-terminally from the scFv domain in the $\alpha$ PSCA-His TM. (AII) The resulting $\alpha$ PSCA-TEV $\mathrm{RS}_{-}-\mathrm{His}$ TM was permanently produced by $3 \mathrm{~T} 3$ cells and also purified via Ni-NTA affinity chromatography out of the supernatants. After TEV protease digestion of the purified TM material the remaining undigested $\alpha \mathrm{PSCA}-\mathrm{TEV}_{\mathrm{RS}}-\mathrm{His} \mathrm{TM}$ portion, the myc-His 6 -tag portion released from the $\alpha \mathrm{PSCA}-\mathrm{TEV}_{\mathrm{RS}}-\mathrm{His} \mathrm{TM}$ as well as the His-tagged TEV protease were separated from TEVdigested $\alpha$ PSCA-w/oHis TM by an additional Ni-NTA affinity chromatography step. After running a SDSPAGE, the purified $\alpha$ PSCA-His TM (BI) and the TEV-digested, purified $\alpha$ PSCA-w/oHis TM (BII) fractions were stained with Coomassie brilliant blue G-250 (BI, BII) or blotted onto a nitrocellulose membrane for detection via $\alpha \mathrm{His} \mathrm{mAb}(\mathbf{C I})$ or $\alpha \mathrm{E} 5 \mathrm{~B} 9 \mathrm{mAb}$ (CII). M, molecular weight marker. Finally, the purity of purified $\alpha$ PSCA-His TM (DI) or TEV-digested, purified $\alpha$ PSCA-w/oHis TM (DII) were analysed by size exclusion HPLC (DI,DII)

tumor cells ${ }^{32}$. As schematically summarised in Fig. 2AI, this UniCAR TM was constructed by fusing variable heavy and light chain domains of the well described $\alpha$ PSCA monoclonal antibody (mAb) (clone MB1) to the UniCAR epitope ${ }^{32,37-39}$. For convenient purification from cell culture supernatant the TM was equipped with an oligo-His-tag at the C-terminus. For differentiation we renamed this TM here as QPSCA-His TM. Based on this construct we designed a novel TM which contained a TEV protease recognition site $\left(\mathrm{TEV}_{\mathrm{RS}}\right)$. The $\mathrm{TEV}_{\mathrm{RS}}$ was introduced upstream of the myc- and His-tag but downstream of the UniCAR epitope E5B9 (Fig. 2AII). After transduction, TMs were permanently expressed in 3 T3 cells as explained previously ${ }^{32,35,36}$ [see also METHODS]. After eukaryotic expression both (His-tagged) TMs were purified from cell culture supernatant using Nickel NTA affinity chromatography. The His-tag of the novel $\alpha \mathrm{PSCA}-\mathrm{TEV}_{\mathrm{RS}}-\mathrm{His} \mathrm{TM}$ was then enzymatically removed using TEV protease digestion followed by an additional Nickel NTA affinity chromatographic step. Thereby the His-tag released from the TM, remaining uncleaved TM and the His-tagged TEV protease were separated from the TM now lacking the His-tag (un-tagged TM). This un-tagged TM was termed $\alpha$ PSCA-w/oHis TM. As expected, the un-tagged TM was found in the flow through fraction.

Both $\alpha$ PSCA TMs, the isolated His-tagged ( $\alpha$ PSCA-His TM) and the un-tagged ( $\alpha$ PSCA-w/oHis TM) TM were biochemically analysed in parallel by SDS-PAGE (Fig. 2B) and immunoblotting (Fig. 2C). Both $\alpha$ PSCA TMs were well produced. Moreover, the UniCAR epitope E5B9 was accessible for $\alpha$ E5B9 mAb detection (Fig. 2CII). 
A aPSCA-His TM

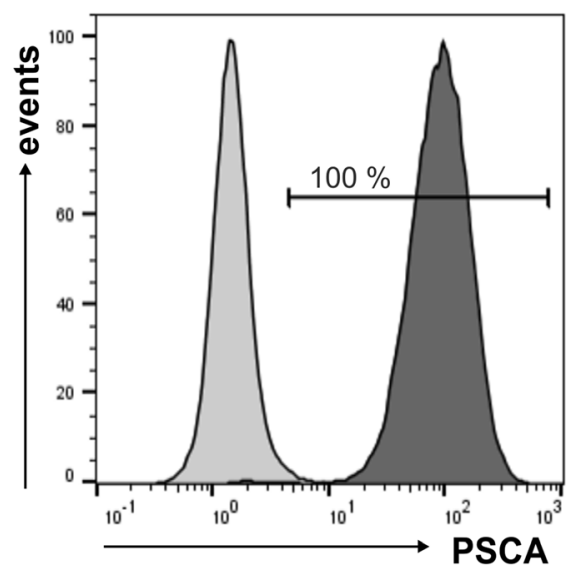

B

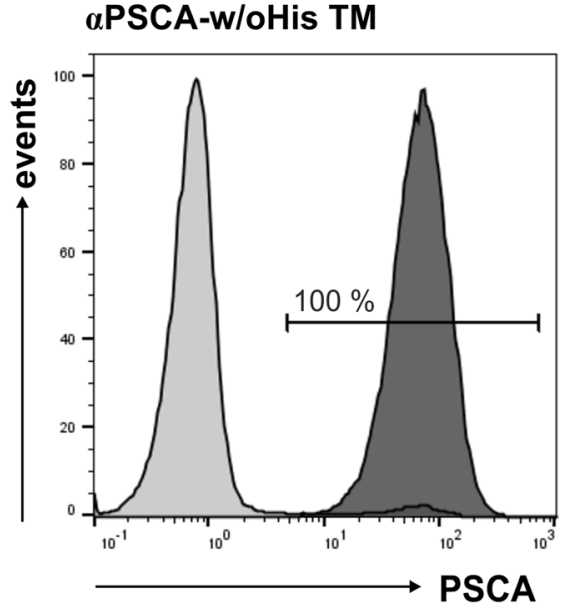

C

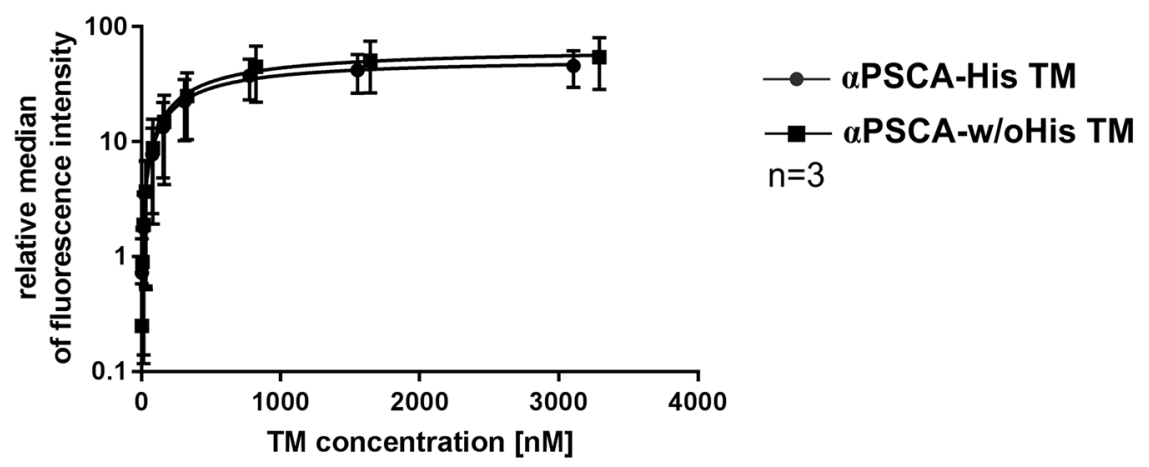

Figure 3. Binding analysis of the $\alpha$ PSCA-His TM and the $\alpha$ PSCA-w/oHis TM to PSCA expressing tumor cells. PC3-PSCA cells were incubated with $\alpha$ PSCA-His TM (A) or $\alpha$ PSCA-w/oHis TM (B). Either $25 \mathrm{ng} / \mu \mathrm{l}(\mathbf{A}, \mathbf{B})$ or different concentrations of the respective TM $(\mathbf{C})$ were used. TM binding was detected via the UniCAR epitope E5B9 using an $\alpha$ E5B9 $\mathrm{mAb}$ and a PE-conjugated $\alpha$-mouse-IgG mAb. After staining, cells were measured by flow cytometry. PC3-PSCA cells that are positively stained with TMs are shown as dark grey graphs in the histograms (A,B). As negative control, the binding of the detection Abs in the absence of the TMs is shown in the bright grey graphs. Binding affinity curves were established for both TMs based on the mean and SEM of three independent experiments $(\mathbf{C})$.

As also shown in Fig. 2C, we could clearly distinguish between the $\alpha$ PSCA-His TM (Fig. 2CI, lane 1) and the $\alpha$ PSCA-w/oHis TM (Fig. 2CI, lane 2). While the un-tagged TM is still reacting with the $\alpha \mathrm{E} 5 \mathrm{~B} 9 \mathrm{mAb}$ recognising the UniCAR epitope (Fig. 2CII, lane 2), it is no more reacting with the mAb directed against the His-tag (Fig. 2CI, lane 2). These data indicate that the His-tag was successfully removed from the original protein.

The purity of the obtained TMs was confirmed by HPLC (Fig. 2D). The achieved purity of both TMs is comparable.

Binding capability of the His-tagged and un-tagged TMs. To compare the binding properties of the His-tagged and un-tagged TM, both TMs were incubated with PSCA expressing PC3 cells and their binding capability was estimated by flow cytometry analysis using an $\alpha \mathrm{E} 5 \mathrm{~B} 9 \mathrm{mAb}$ recognising their C-terminal UniCAR epitope E5B9. As shown in Fig. 3(A-C), both TMs can efficiently bind to the target cells. Most importantly, after binding of both TMs to their target antigen PSCA, the UniCAR epitope of the TMs can still be recognised by the related $\alpha \mathrm{E} 5 \mathrm{~B} 9 \mathrm{mAb}$, which is an absolute prerequisite for the tumor-specific redirection of UniCAR $\mathrm{T}$ cells via TMs. In addition, increasing concentrations of both TMs were used to estimate binding affinities. As shown in Fig. 3C, we calculated comparable $K_{D}$ values of $407 \mathrm{nM}$ for the $\alpha$ PSCA-His TM and $476 \mathrm{nM}$ for the $\alpha$ PSCA-w/ oHis TM.

Killing of PSCA expressing tumor cells by redirection of UniCAR T cells via His-tagged and un-tagged $\alpha$ PSCA TMs. In order to address the question, whether removal of the His-tag influences the functionality of the $\alpha \mathrm{PSCA} s \mathrm{scF}$ domain, chromium release assays were performed [see METHODS]. Human $\mathrm{T}$ cells were genetically modified to express signalling UniCARs comprising the co-stimulatory CD28 as well as the activating $\mathrm{CD} 3 \zeta$ domain (UniCAR $\mathrm{CD} 28 / \zeta$ ) by lentiviral transduction as described previously ${ }^{32}$ [see also METHODS]. In addition, human T cells presenting UniCARs without any intracellular signalling domains (UniCAR stop) or expressing only the marker protein EGFP (vector control) were generated by lentiviral 
A

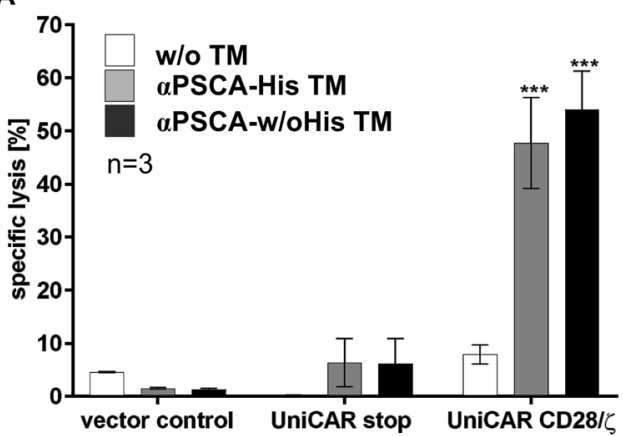

B

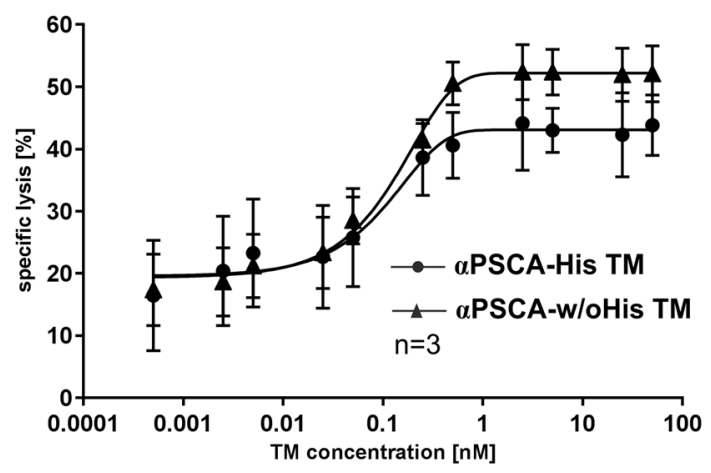

Figure 4. Comparison of specific tumor cell lysis by redirection of UniCAR T cells via the $\alpha$ PSCA-His TM and the $\alpha$ PSCA-w/oHis TM. In a standard chromium release assay UniCAR CD28/ $\zeta$ armed T cells were cocultivated with ${ }^{51} \mathrm{Cr}$-labelled PC3-PSCA tumor cells in the absence of TM (A, w/o TM) or in the presence of $50 \mathrm{nM}(\mathbf{A})$ or indicated amounts of the respective TM (B) at an effector to target cell ratio of 5:1 for $24 \mathrm{~h}$. Instead

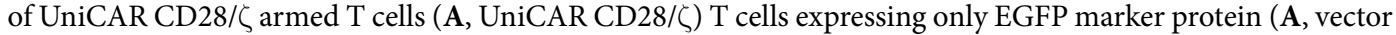
control) or the UniCAR stop construct missing any signalling domains (A, UniCAR stop) were used as controls. By using different TM amounts the range of working concentration was estimated (B). Mean of specific lysis and SEM are shown for three individual T cell donors. For statistical analysis two way ANOVA with Tukey's (A) or Sidak's $($ B) multiple comparisons test was performed. (***p $<0.001$; with respect to vector control $+\mathrm{TM}$, UniCAR stop + TM or UniCAR CD28/ל w/o TM).

transduction and used as negative controls. For comparable reasons of different donors transduced T cells were sorted to $>90 \%$ purity.

To analyse killing capabilities, UniCAR T cells were cultured together with ${ }^{51} \mathrm{Cr}$-loaded PC3-PSCA cells at an effector to target cell (E:T) ratio of 5:1 in the absence or presence of the respective TM for $24 \mathrm{~h}$.

In agreement with previous data, only $\mathrm{T}$ cells armed with signalling UniCAR CD28/ $\zeta$ constructs were able to effectively eradicate tumor cells in the presence of the His-tagged or un-tagged TM (Fig. 4A). In contrast, target cells were not attacked by modified T cells expressing UniCAR stop or only EGFP marker protein. As no specific lysis was detected in the absence of any TM (Fig. 4A, w/o TM), killing of PSCA-positive PC3 cell line occurred in a strictly TM-dependent manner. Both the His-tagged and the un-tagged TM can redirect UniCAR T cells to kill PSCA-positive target cells with similar efficacy. In order to calculate $\mathrm{EC}_{50}$ values of both $\mathrm{TMs}$, titration experiments were performed (Fig. 4B). As expected, the killing correlates with the concentration of the respective TM. Increasing the concentration of both TMs (Fig. 4B) reaches a plateau at a concentration of about $1 \mathrm{nM}$. The calculated $\mathrm{EC}_{50}$ values for the $\alpha$ PSCA-His TM and the $\alpha$ PSCA-w/oHis TM were estimated at equal levels with $0.10 \mathrm{nM}$ and $0.11 \mathrm{nM}$, respectively. Although the maximal tumor cell lysis mediated by the $\alpha \mathrm{PSCA}-\mathrm{w} / \mathrm{oHis} \mathrm{TM}$ in combination with UniCAR T cells seems to be slightly higher than using the $\alpha$ PSCA-His TM, there was no significant difference between the killing capacity of both TMs at any measured TM concentrations.

Activation of UniCAR T cells redirected via His-tagged and un-tagged $\alpha$ PSCA TMs. In order to further verify the activation and exhaustion status of UniCAR CD28/ $\zeta \mathrm{T}$ cells, they were co-cultured with PSCA-positive target cells at an E:T ratio of 5:1 with or without $25 \mathrm{nM}$ of the respective TM. As negative controls, T cells expressing UniCAR stop constructs or transduced with the vector control were used. After $24 \mathrm{~h}$ of co-cultivation, CD69 and PD1 surface expression on CD4- and CD8-positive T cell subpopulations were analysed by flow cytometry. As shown in Fig. 5A, an upregulation of CD69 activation marker occurs for both CD4 ${ }^{+}$ (Fig. 5AI) and $\mathrm{CD}^{+}$(Fig. 5AII) UniCAR T cells in a strict tumor-specific and TM-dependent manner, while the activation level of UniCAR T cells redirected by the His-tagged or un-tagged TM was indistinguishable. In contrast, in the absence of target cells or TMs no CD69 upregulation was observed. Additionally, CD69 level was not increased using control T cells (vector control or UniCAR stop) in the presence of TM and target cells. 

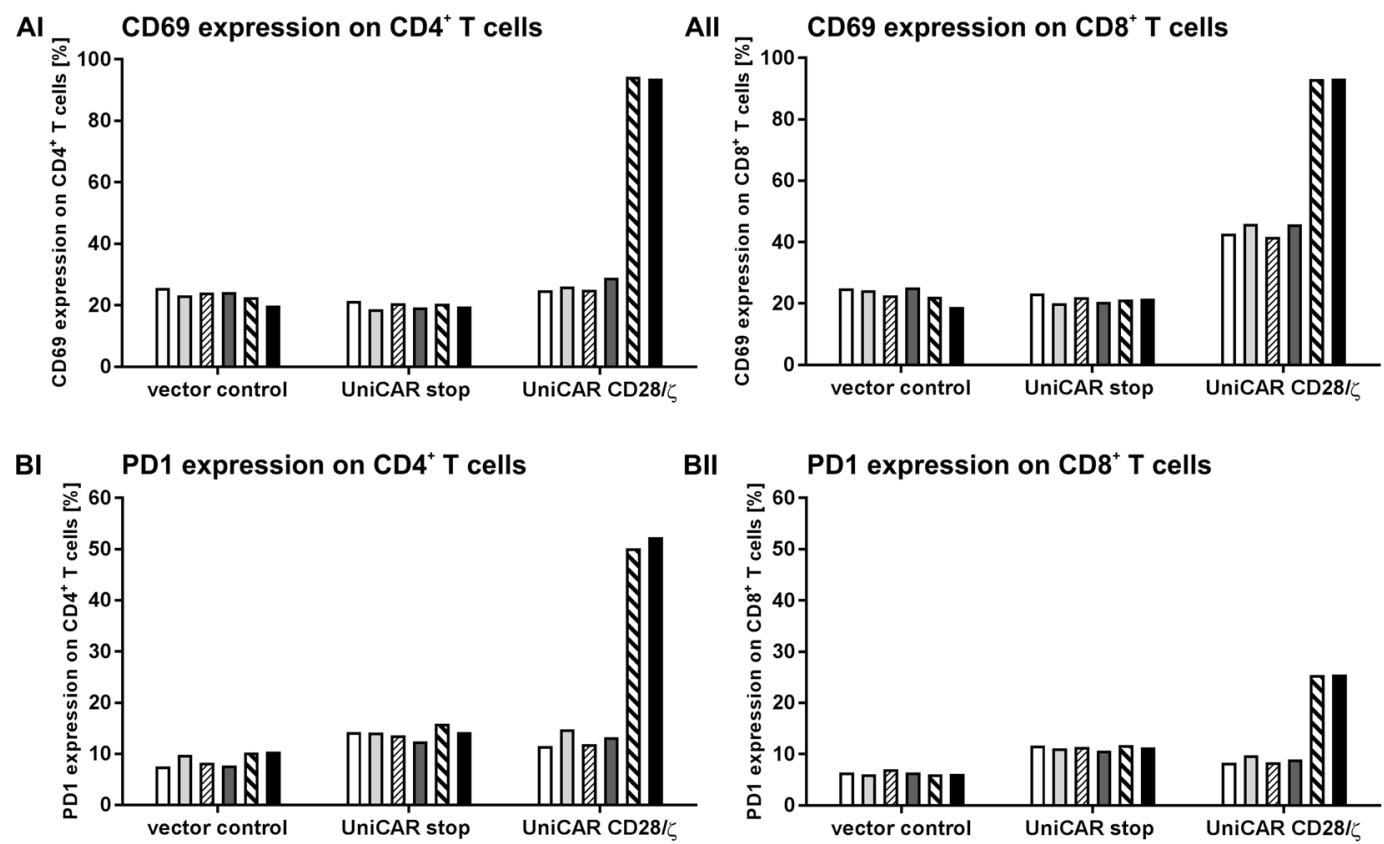

C
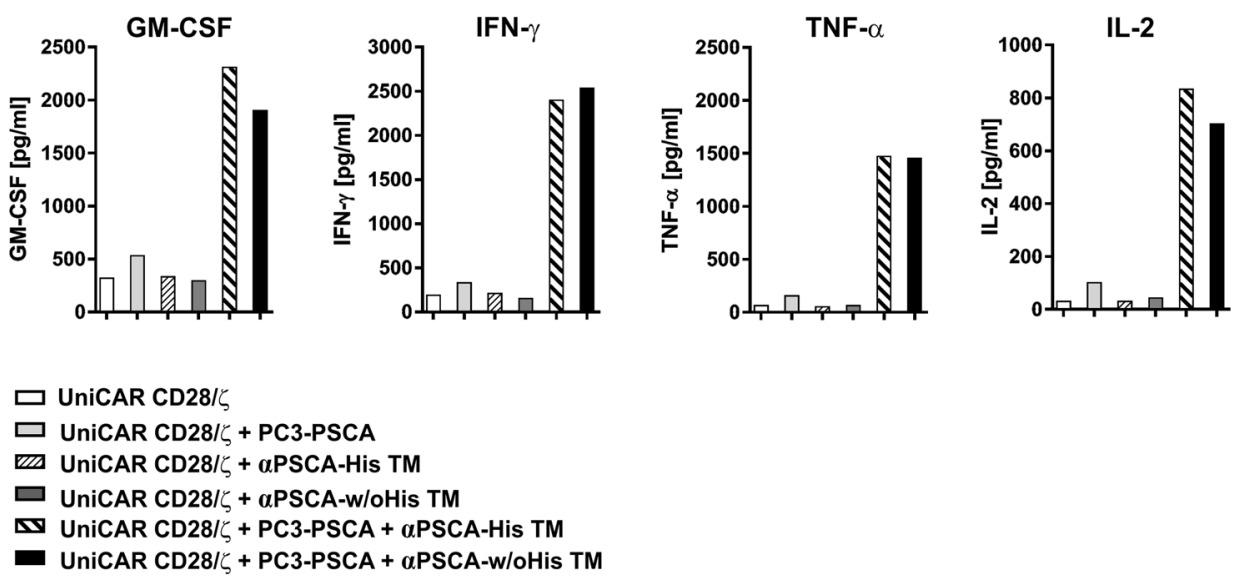

Figure 5. Activation and exhaustion of UniCAR T cells and cytokine release from UniCAR T cells redirected to PC3-PSCA tumor cells via the $\alpha$ PSCA-His TM and the $\alpha$ PSCA-w/oHis TM. UniCAR CD28/ $\zeta$ expressing human T cells (UniCAR CD28/ $)$ ) were incubated with or without PC3-PSCA tumor cells (effector to target cell ratio of 5:1) either in the absence or presence of $25 \mathrm{nM}$ TM. All experiments were performed in triplicates. After 24h, triplicates were pooled and CD69 (AI,AII) and PD1 (BI,BII) expression were estimated on CD4(AI,BI) or CD8-positive (AII,BII) T cell subpopulations by staining with an $\alpha$ CD69-APC mAb or $\alpha$ PD1-PE $\mathrm{mAb}$ and flow cytometry. T cell subpopulations were discriminated by staining with an $\alpha \mathrm{CD} 4-\mathrm{PE}-\mathrm{Vio} 770$ and $\alpha \mathrm{CD} 8$-VioBlue $\mathrm{mAb}$. As additional controls, human T cells expressing only EGFP marker protein (vector control) or the UniCAR stop construct lacking any signalling domains (UniCAR stop) served. In addition, after $24 \mathrm{~h}$ of co-cultivation, supernatants of triplicates were pooled and afterwards cytokines secreted into cell culture supernatants were estimated using the MACSPlex Cytokine 12 kit (C). Shown cytokines were detected in relevant amounts. CD69, PD1 and cytokine profile for $\alpha$ PSCA-His TM and $\alpha$ PSCA-w/oHis TM are shown in comparison for one representative $\mathrm{T}$ cell donor.

Similarly, the expression of PD1 surface marker on UniCAR CD28/ $\zeta$ T cells is markedly increasing only in the presence of target cells and specific TM (Fig. 5B). The PD1 expression level was comparably high for His-tagged and un-tagged TM.

Cytokine release from UniCAR T cells redirected via His-tagged and un-tagged $\alpha$ PSCA TMs. Amounts of cytokines secreted from redirected UniCAR T cells into cell culture supernatants were estimated using the MACSPlex Cytokine 12 kit (human) as described previously ${ }^{31}$ [see also METHODS]. For cytokine profile analysis, UniCAR CD28/ $\zeta$ T cells were incubated alone or together with PSCA-positive PC3 target cells either with $(25 \mathrm{nM})$ or without the respective TM for $24 \mathrm{~h}$. Comparative cytokine profile for both $\alpha$ PSCA TMs containing or lacking the His-tag is shown for one representative donor in Fig. $5 \mathrm{C}$. The secretion 
A PC3-PSCA/PSMA-IUc

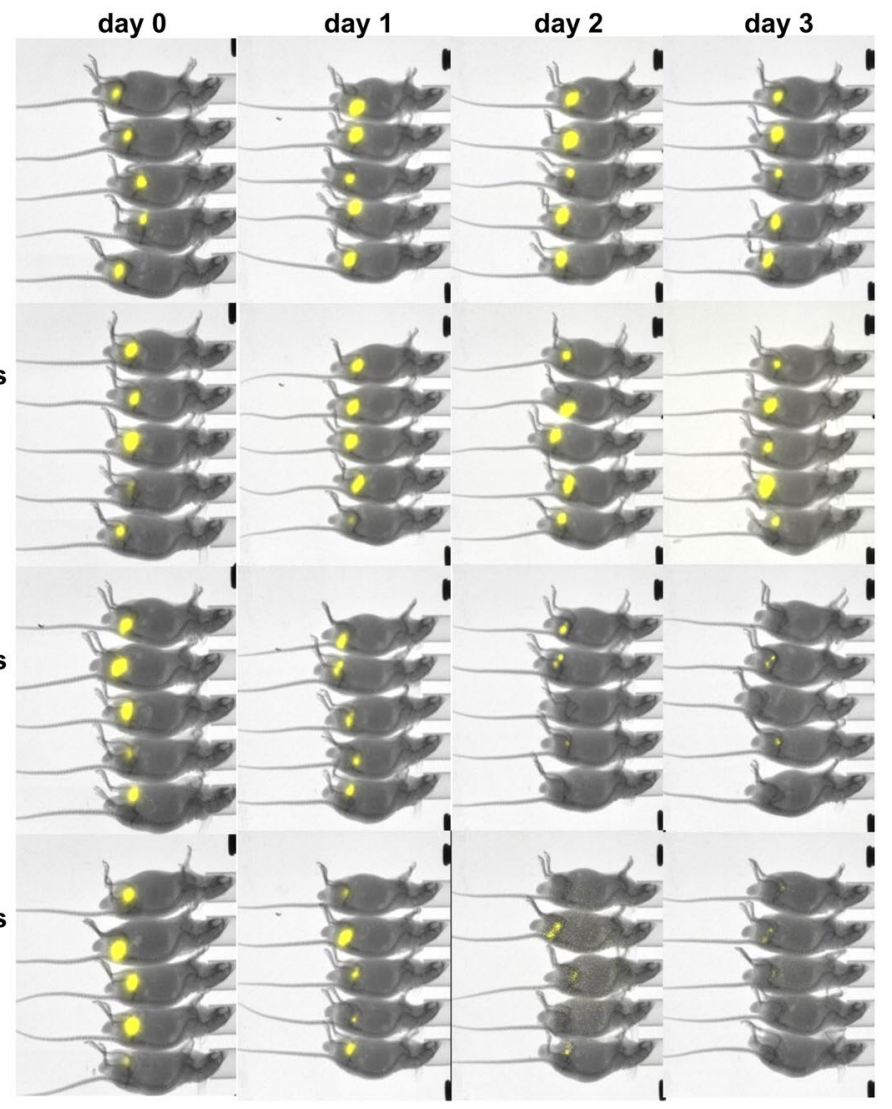

Figure 6. Tumor cell killing by redirection of UniCAR T cells via the $\alpha$ PSCA-His TM and the $\alpha$ PSCA-w/oHis TM in vivo. For studies in experimental mice four groups of male Rj:NMRI-Foxn $1^{\mathrm{nu} / \mathrm{nu}}$ mice each consisting of five animals were distinguished. In the treated groups luciferase expressing PC3-PSCA/PSMA tumor cells $\left(0.5 \times 10^{6}\right)$ were premixed with UniCAR CD28/ $\zeta$ armed T cells $\left(0.5 \times 10^{6}\right)$ in the presence of $10 \mu \mathrm{g} \alpha \mathrm{PSCA}-\mathrm{His}$ TM (C) or $\alpha$ PSCA-w/oHis TM (D) and subcutaneously co-injected into the right hind mouse flank. In the

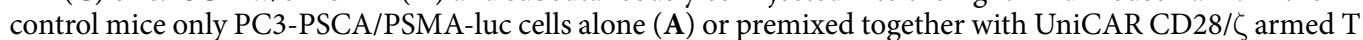
cells in the absence of any TM (B) were injected. Luminescence imaging of anesthetised mice was performed at day zero (day 0 ) and followed for three days (day 1 , day 2 , day 3 ).

of the cytokines GM-CSF, IFN- $\gamma$, TNF- $\alpha$, and IL-2 was clearly increased upon incubation of UniCAR CD28/ $\zeta$ armed T cells together with PC3-PSCA target cells in the presence of respective $\alpha$ PSCA TM. No other cytokines, including IL-6, could be detected at relevant concentrations. In the negative controls (UniCAR CD28/ $\zeta$ T cells either alone or with TM or with PC3-PSCA cells without TM) no or only background levels of cytokines could be measured. Consequently, collected data suggest that UniCAR T cells secrete pro-inflammatory cytokines in a strictly target-specific and TM-dependent manner. Obviously, the amounts of secreted cytokines were similar for both TMs containing or lacking the His-tag (Fig. 5C).

Anti-tumor effects of UniCAR T cells redirected by His-tagged and un-tagged $\alpha$ PSCA TMs in experimental mice. To confirm the TM-dependent tumor killing capacity of UniCAR expressing T cells in vivo, a mouse tumor xenograft model was applied. Four groups of male Rj:NMRI-Foxn $1^{\text {nu/nu }}$ mice each consisting of five animals were distinguished. Mixtures $(100 \mu \mathrm{l})$ of $0.5 \times 10^{6}$ firefly luciferase expressing PSCA/

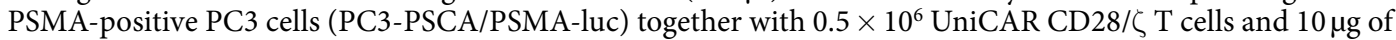
His-tagged (Fig. 6C) or un-tagged (Fig. 6D) TM were subcutaneously injected in the right mouse flank. As controls served $0.5 \times 10^{6} \mathrm{PC} 3$-PSCA/PSMA-luc cells alone or mixed with $0.5 \times 10^{6}$ UniCAR CD28/ $\zeta \mathrm{T}$ cells without any TM (Fig. 6A,B, respectively). Luciferase activity was analysed starting at day zero (Fig. 6, day 0), followed at day one (Fig. 6, day 1), day two (Fig. 6, day 2), and day three (Fig. 6, day 3). As shown in Fig. 6, in all treated animals no considerable luciferase activity was detectable already at day three, whereas in the control mice luciferase activity could easily be detected. According to these results UniCAR T cells can effectively kill tumor cells when armed with a TM. There was no obvious difference between the $\alpha$ PSCA-His TM and the $\alpha$ PSCA-w/oHis TM indicating that the His-tag has also no obvious effect on redirection of UniCAR T cells towards tumor cells in vivo.

In vivo biodistribution of radiolabelled TMs. In order to visualise that TMs can bind at the tumor site in vivo and to compare the biodistribution and kinetics of the TMs in the Rj:NMRI-Foxn $1^{\mathrm{nu} / \mathrm{nu}}$ mouse tumor model, the $\alpha$ PSCA-His TM and $\alpha$ PSCA-w/oHis TM were conjugated with NODAGA. According to MALDI-TOF analysis each TM was modified with approximately two NODAGA molecules. Afterwards the modified TMs were 
Al

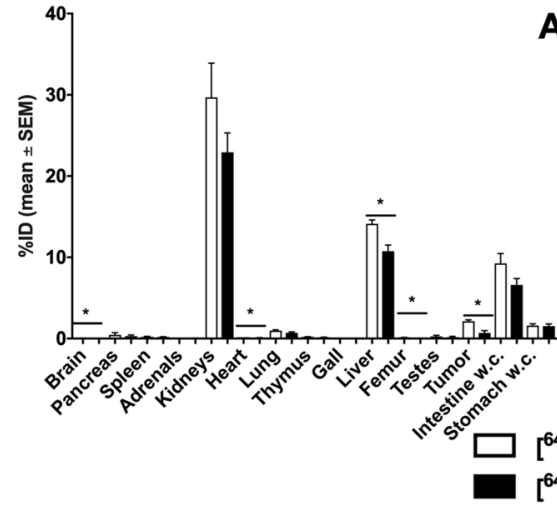

BI

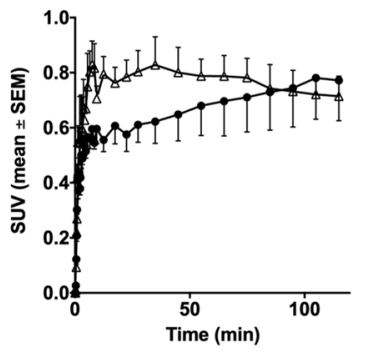

BIII

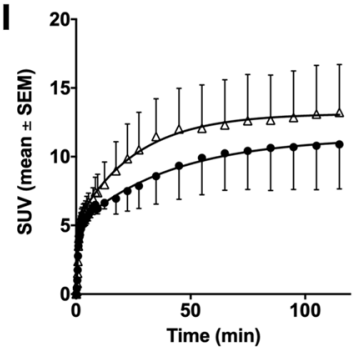

All

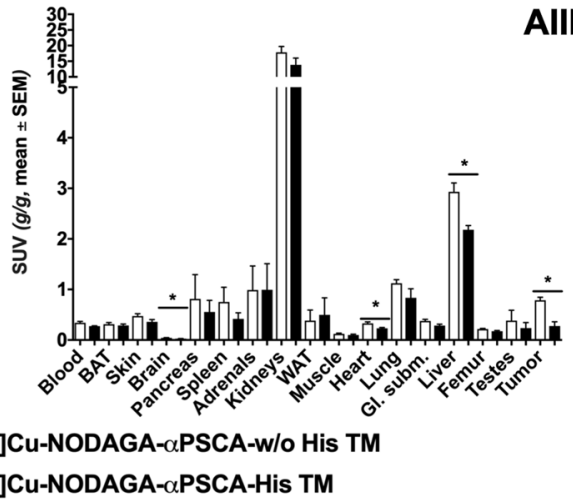

AllI

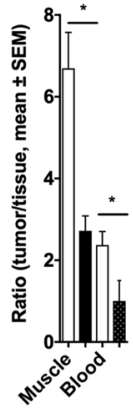

BII

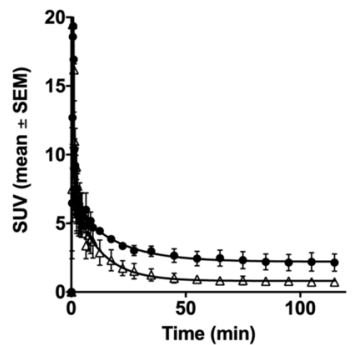

BIV

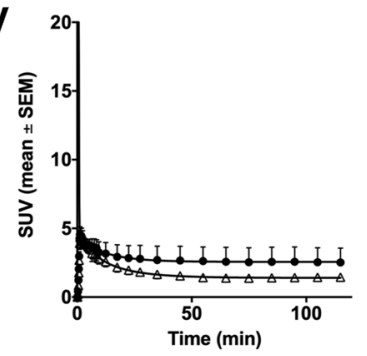

Cl

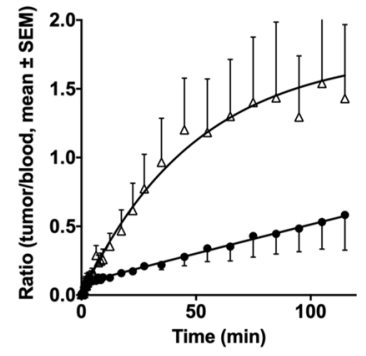

Cll

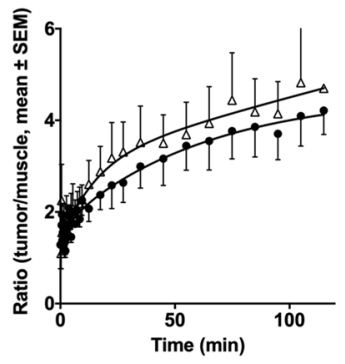

$\triangle\left[{ }^{64} \mathrm{Cu}\right]$ Cu-NODAGA- $\alpha$ PSCA-w/o His TM

- $\left[{ }^{64} \mathrm{Cu}\right]$ Cu-NODAGA-aPSCA-His TM

Figure 7. In vivo biodistribution and PET-biokinetics of ${ }^{64} \mathrm{Cu}$-radiolabelled TMs. (A) The biodistribution of the $\left[{ }^{64} \mathrm{Cu}\right] \mathrm{Cu}$-NODAGA- $\alpha$ PSCA-His TMs or $\left[{ }^{64} \mathrm{Cu}\right] \mathrm{Cu}-\mathrm{NODAGA}-\alpha$ PSCA-w/oHis TMs was determined 120 min after single intravenous injection in male Rj:NMRI-Foxn $1^{\text {nu/nu }}$ mice subcutaneously bearing luciferase expressing PC3-PSCA/PSMA tumors on the right hind leg by tissue and organ extraction. The distribution is presented as percentage of the total activity amount of the injected dose (AI, \% ID) and the activity concentration in the tissues and organs (AII, SUV). In addition, the activity concentration is expressed as the ratios of tumor to muscle and tumor to blood (AIII). Mean and SEM of three animals are shown (A). For comparison of both TMs the student's $t$-test was performed $\left({ }^{*} p<0.05\right)$. $(\mathbf{B}, \mathbf{C})$ The kinetics of the $\left[{ }^{64} \mathrm{Cu}\right] \mathrm{Cu}-$ NODAGA- $\alpha$ PSCA-His TMs or $\left[{ }^{64} \mathrm{Cu}\right] \mathrm{Cu}-\mathrm{NODAGA}-\alpha$ PSCA-w/oHis TM were measured over $120 \mathrm{~min}$ after single intravenous injection in male Rj:NMRI-Foxn $1^{\text {nu/nu }}$ mice bearing subcutaneous luciferase expressing PC3-PSCA/PSMA tumors on the right hind leg by dynamic small animal PET-imaging. The regions of interest (ROIs) were analysed for the tumors (BI), blood (BII), kidneys (BIII), liver (BIV), and the ratios of the tumor to blood (CI) and tumor to muscle (CII) were calculated. Mean and SEM of four animals are shown (B,C).

conjugated with ${ }^{64} \mathrm{Cu}^{2+}$ showing a short positron range in order to get high-resolution PET images in experimental mice. The radiochemical purity reached 91 to $94 \%$ with specific activities from 28 to $40 \mathrm{GBq} / \mu \mathrm{mol}$.

The results of the biodistribution experiments are summarised in Fig. 7A and the Tables 1 and 2. The biodistribution of the ${ }^{64} \mathrm{Cu}$-radiolabelled TMs was determined $120 \mathrm{~min}$ after single intravenous injection in male Rj:NMRI-Foxn $1^{\text {nu/nu }}$ mice bearing subcutaneous luciferase expressing PC3-PSCA/PSMA tumors on the right hind leg by tissue and organ extraction. The activity amounts of both ${ }^{64} \mathrm{Cu}$-labelled TMs, the $\alpha$ PSCA-His TM as well as the $\alpha$ PSCA-w/oHis TM, were similar in the majority of analysed organs and tissues (Fig. 7AI-AII, Table 1, Table 2). However, the $\left[{ }^{64} \mathrm{Cu}\right] \mathrm{Cu}-\mathrm{NODAGA}-\alpha$ PSCA-w/oHis TM accumulation (\% ID) was significantly higher in the brain, heart, liver, femur, and tumor (Fig. 7AI, Table 1). Accordingly, the activity concentration (SUV) values of $\left[{ }^{64} \mathrm{Cu}\right] \mathrm{Cu}-\mathrm{NODAGA}-\alpha \mathrm{PSCA}-\mathrm{w} / \mathrm{oHis}$ TM were also higher in the tumor, brain, heart, and liver (Fig. 7AII, Table 2) and also for the tumor to background ratios (Fig. 7AIII, Table 2) in comparison to the [ $\left.{ }^{64} \mathrm{Cu}\right]$ Cu-NODAGA- $\alpha$ PSCA-His TM. 


\begin{tabular}{|c|c|c|c|}
\hline organs & 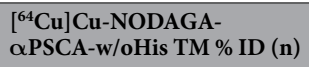 & 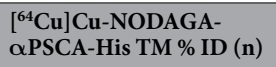 & $\mathbf{P}$ \\
\hline Brain & $0.053 \pm 0.006(3)$ & $0.040 \pm 0.010(3)$ & 0.038 \\
\hline Pancreas & $0.453 \pm 0.465(3)$ & $0.287 \pm 0.245(3)$ & \\
\hline Spleen & $0.213 \pm 0.119(3)$ & $0.187 \pm 0.046(3)$ & \\
\hline Adrenals & $0.037 \pm 0.029(3)$ & $0.040 \pm 0.044(3)$ & \\
\hline Kidneys & $29.69 \pm 7.305(3)$ & $22.94 \pm 4.12(3)$ & \\
\hline Heart & $0.193 \pm 0.006(3)$ & $0.123 \pm 0.015(3)$ & 0.001 \\
\hline Lung & $0.980 \pm 0.185(3)$ & $0.720 \pm 0.193(3)$ & \\
\hline Thymus & $0.200 \pm 0.03(3)$ & $0.150 \pm 0.036(3)$ & \\
\hline Gall & $0.027 \pm 0.006(3)$ & $0.020 \pm 0.001(3)$ & \\
\hline Liver & $14.13 \pm 0.825(3)$ & $10.76 \pm 1.31(3)$ & 0.019 \\
\hline Femur & $0.133 \pm 0.015(3)$ & $0.107 \pm 0.006(3)$ & 0.037 \\
\hline Testes & $0.267 \pm 0.231(3)$ & $0.183 \pm 0.162(3)$ & \\
\hline Tumor & $2.13 \pm 0.306(3)$ & $0.703 \pm 0.493(3)$ & 0.013 \\
\hline Intestine w.c. & $9.25 \pm 2.110(3)$ & $6.61 \pm 1.36(3)$ & \\
\hline Stomach w.c. & $1.61 \pm 0.350(3)$ & $1.54 \pm 0.45(3)$ & \\
\hline
\end{tabular}

Table 1. Biodistribution of $\left[{ }^{64} \mathrm{Cu}\right] \mathrm{Cu}-\mathrm{NODAGA}-\alpha$ PSCA-His TMs and $\left[{ }^{64} \mathrm{Cu}\right] \mathrm{Cu}-\mathrm{NODAGA}-\alpha \mathrm{PSCA}-\mathrm{w} /$ oHis TMs in Rj:NMRI Foxn $1^{\text {nu/nu }}$ PC3-PSCA/PSMA tumor bearing mice at 120 min after single intravenous injection. The values show the mean and SD of the percentage of the total activity amount of the injected dose (\% ID) in selected organs and the number of analysed animals (n). For comparison of both TMs the student's $\mathrm{t}$-test was performed. The calculated $\mathrm{p}$ values are shown if they are lower than 0.05 . Intestine w.c., intestine with content; stomach w.c., stomach with content.

\begin{tabular}{|c|c|c|c|}
\hline Organs Tissues & $\begin{array}{l}{\left[{ }^{64} \mathrm{Cu}\right] \mathrm{Cu}-\mathrm{NODAGA}-\alpha \text { PSCA-w/ }} \\
\text { oHis TM SUV (n) }\end{array}$ & $\begin{array}{l}{\left[{ }^{64} \mathrm{Cu}\right] \mathrm{Cu}-\mathrm{NODAGA}-} \\
\alpha \text { PSCA-His TM SUV (n) }\end{array}$ & $\mathbf{P}$ \\
\hline Blood & $0.339 \pm 0.016(3)$ & $0.275 \pm 0.011$ & \\
\hline BAT & $0.312 \pm 0.046(3)$ & $0.289 \pm 0.038(3)$ & \\
\hline Skin & $0.474 \pm 0.063(3)$ & $0.356 \pm 0.065(3)$ & \\
\hline Brain & $0.043 \pm 0.005(3)$ & $0.026 \pm 0.003(3)$ & 0.019 \\
\hline Pancreas & $0.814 \pm 0.676(3)$ & $0.555 \pm 0.325$ & \\
\hline Spleen & $0.752 \pm 0.41(3)$ & $0.418 \pm 0.168(3)$ & \\
\hline Adrenals & $0.988 \pm 0.673(3)$ & $0.992 \pm 0.732(3)$ & \\
\hline Kidneys & $17.84 \pm 2.640(3)$ & $13.85 \pm 3.066(3)$ & \\
\hline WAT & $0.383 \pm 0.298$ (3) & $0.496 \pm 0.477(3)$ & \\
\hline Muscle & $0.121 \pm 0.02(3)$ & $0.098 \pm 0.024(3)$ & \\
\hline Heart & $0.329 \pm 0.041(3)$ & $0.231 \pm 0.022$ & 0.040 \\
\hline Lung & $1.122 \pm 0.1(3)$ & $0.834 \pm 0.255$ & \\
\hline Gl. subm. & $0.376 \pm 0.046(3)$ & $0.285 \pm 0.039(3)$ & \\
\hline Liver & $2.93 \pm 0.249(3)$ & $2.18 \pm 0.122(3)$ & 0.018 \\
\hline Femur & $0.218 \pm 0.014(3)$ & $0.174 \pm 0.019(3)$ & \\
\hline Testes & $0.383 \pm 0.289(3)$ & $0.235 \pm 0.155(3)$ & \\
\hline Tumor & $0.787 \pm 0.081(3)$ & $0.277 \pm 0.100(3)$ & 0.007 \\
\hline Tumor / blood & $2.371 \pm 0.356(3)$ & $1.003 \pm 0.408$ & 0.018 \\
\hline Tumor / muscle & $6.694 \pm 1.242(3)$ & $2.721 \pm 0.515$ & 0.013 \\
\hline
\end{tabular}

Table 2. Biodistribution of $\left[{ }^{64} \mathrm{Cu}\right] \mathrm{Cu}-\mathrm{NODAGA}-\alpha$ PSCA-His TMs and $\left[{ }^{64} \mathrm{Cu}\right] \mathrm{Cu}-\mathrm{NODAGA}-\alpha \mathrm{PSCA}-\mathrm{w} /$ oHis TMs in Rj:NMRI Foxn $1^{\text {nu/nu }}$ PC3-PSCA/PSMA tumor bearing mice at 120 min after single intravenous injection. The values show the mean and SD of activity concentration in selected organs as SUV, the tumor to muscle and tumor to blood ratios and the number of analysed animals (n). For comparison of both TMs the student's t-test was performed. The calculated $p$ values are shown if they are lower than 0.05 . Gl. subm., glandula submandibularis.

In vivo PET-biokinetics of radiolabelled TMs. The dynamic PET measurements show similar behaviour of both radiolabelled TMs in the measured organs (Fig. 7BI-BIV) with a slight tendency of a faster blood clearance of the $\left[{ }^{64} \mathrm{Cu}\right] \mathrm{Cu}-\mathrm{NODAGA}-\alpha \mathrm{PSCA}-\mathrm{w} / \mathrm{oHis} \mathrm{TM}\left(\mathrm{T}_{1 / 2} 8.28 \mathrm{~min}\right)$ in comparison to $\left[{ }^{64} \mathrm{Cu}\right]$ $\mathrm{Cu}-\mathrm{NODAGA}-\alpha$ PSCA-His TM $\left(\mathrm{T}_{1 / 2} 12.5 \mathrm{~min}\right)$ resulting in a higher tumor accumulation for the $\left[{ }^{64} \mathrm{Cu}\right]$ $\mathrm{Cu}-\mathrm{NODAGA}-\alpha \mathrm{PSCA}-\mathrm{w} / \mathrm{oHis} \mathrm{TM}$ and improved tumor to blood ratio after $2 \mathrm{~h}$ (Fig. $7 \mathrm{CI}$ ). The other tumor to background parameter, the tumor to muscle ratio, was similar for both TMs and reached values larger than four (Fig. 7CII). 
Al aPSCA-His TM

All

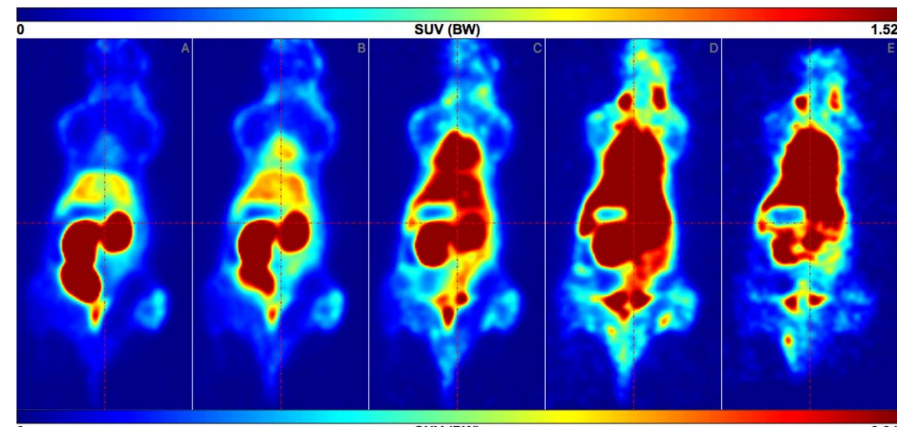

aPSCA-w/oHis TM

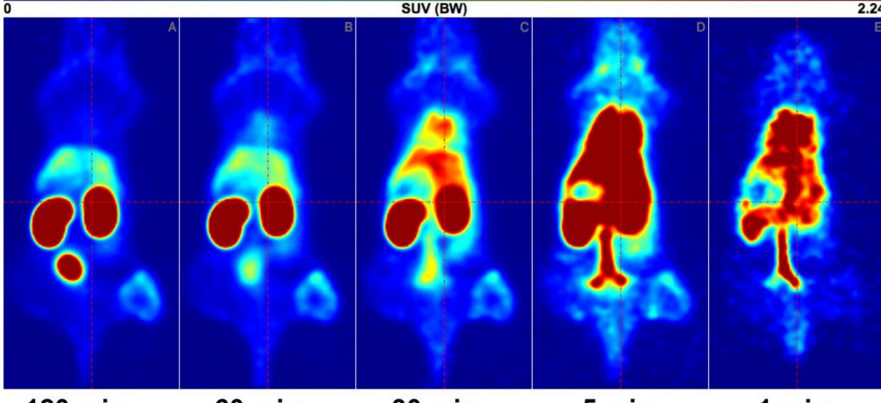

$120 \mathrm{~min}$

$60 \mathrm{~min}$

$30 \mathrm{~min}$

5 min

$1 \mathrm{~min}$

BI no tumor

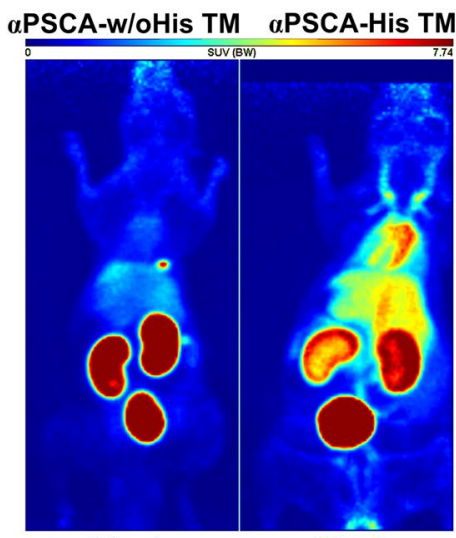

90 min

90 min

\section{Bll tumor}

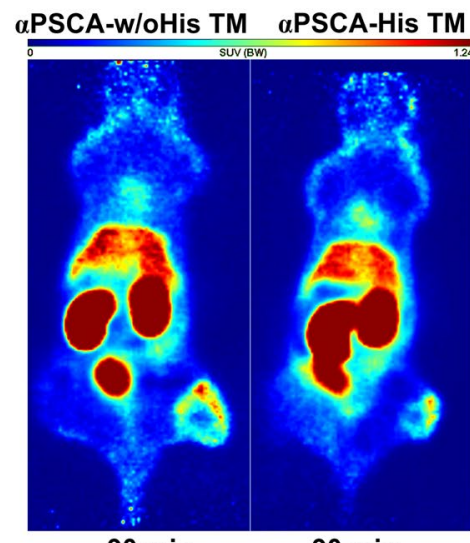

$90 \mathrm{~min}$

90 min

Figure 8. PET-images of ${ }^{64} \mathrm{Cu}$-radiolabelled TMs. $\left[{ }^{64} \mathrm{Cu}\right] \mathrm{Cu}-\mathrm{NODAGA}-\alpha$ PSCA-His TMs or $\left[{ }^{64} \mathrm{Cu}\right]$ $\mathrm{Cu}-\mathrm{NODAGA}-\alpha$ PSCA-w/oHis TMs were intravenously injected in male Rj:NMRI-Foxn $1^{\text {nu/nu }}$ mice with subcutaneous PC3-PSCA/PSMA-luciferase tumors. The images show the distribution of $\left[{ }^{64} \mathrm{Cu}\right] \mathrm{Cu}-\mathrm{NODAGA}-$ $\alpha$ PSCA-His TMs (AI) or $\left[{ }^{64} \mathrm{Cu}\right] \mathrm{Cu}-\mathrm{NODAGA}-\alpha \mathrm{PSCA}-w / \mathrm{oHis}$ TMs (AII) as maximum intensity projections (MIPs) calculated for midframe times of 1, 5, 30, 60, and $120 \mathrm{~min}$ p.i. (A). In addition, the distribution of both radiotracers was imaged in tumor-free animals (BI) as well as in tumor bearing animals (BII) after $90 \mathrm{~min}$ p.i.

In vivo PET-imaging of radiolabelled TMs. $\quad\left[{ }^{64} \mathrm{Cu}\right] \mathrm{Cu}-\mathrm{NODAGA}-\alpha \mathrm{PSCA}-\mathrm{His} \mathrm{TM}$ or $\left[{ }^{64} \mathrm{Cu}\right]$ Cu-NODAGA- $\alpha$ PSCA-w/oHis TM were injected into Rj:NMRI-Foxn $1^{\text {nu/nu }}$ mice bearing PC3-PSCA/ PSMA-luciferase tumors. As shown in the PET-images (Fig. 8) biodistribution and kinetics of both the radiolabelled His-tagged (Fig. 8AI) and un-tagged (Fig. 8AII) TMs were similar in experimental mice 1, 5, 30, 60, 90, and $120 \mathrm{~min}$ p.i. Both the His-tagged as well as the un-tagged radiolabelled TMs allow the visualisation of established PC3-PSCA/PSMA-luciferase tumors and their heterogeneity in mice as the tumors were clearly separated from normal tissue (Fig. 8AI-II, 8BII). PET-images from tumor-free mice taken $90 \mathrm{~min}$ after injection of radiolabelled TMs demonstrate a lower blood pool activity of the $\left[{ }^{64} \mathrm{Cu}\right] \mathrm{Cu}-\mathrm{NODAGA}-\alpha$ PSCA-w/oHis TM (Fig. 8BI).

\section{Discussion}

CAR T cell therapy has shown impressive therapeutic effects in haematological malignancies ${ }^{10-13}$ which recently resulted in the approval of two of CD19-targeting CAR T cells by the U.S. FDA, tisagenlecleucel (Kymriah ${ }^{\circledR}-$ Novartis) in leukemia and lymphoma and axicabtagene ciloleucel (Yescarta ${ }^{\circledR}-$ Kite) in lymphoma. In spite of the impressing efficacy of these CAR T cell therapies still a lot of challenges remain to be solved especially before CAR T cells may also efficiently work for solid tumors. Among several problems of CAR T cell therapies, one big hurdle is that no target antigen is known strictly expressed only on tumor cells. As a consequence, CAR T cells are 
directed to TAAs being overexpressed on tumors. However, TAAs are not limited to tumor cells but the same targets may also be expressed on healthy organs and tissues, potentially leading to even fatal side effects. Moreover, the steering of CAR T cells is difficult. Once adoptively transferred into a patient, it is almost impossible to predict how the CAR T cells will behave in the patient. As a living drug, CAR T cells will proliferate once they find their target. Moreover, the proliferating activated CAR T cells will produce cytokines. However, at this time point only little is known about the tumor mass and how the individual CAR T cells will respond. Therefore, it is almost impossible to predict how CAR T cells will behave after adoptive transfer. As there is no safety switch in CAR T cells severe or even life-threating side effects such as tumor lysis syndrome and cytokine release syndrome may occur. In order to reduce the risk of such side effects, in 2014 we introduced the switchable modular UniCAR platform technology ${ }^{25,30-36}$. UniCAR T cells per se are inert. Their activity can be titrated via the application of a TM.

TMs are commonly bifunctional recombinant proteins. For a rapid purification, the TMs are equipped with an oligo-His-tag at the C-terminus. Although some recombinant His-tagged proteins are clinically used ${ }^{40}$, concerns about the presence of an oligo-His-tag in TMs of the UniCAR system came up during discussions with the legal authorities. Tagging of recombinant proteins with an oligo-His-tag is an ideal method for many applications because it allows an easy identification as well as rapid, high selective and efficient one-step purification via immobilized metal ion affinity chromatography (IMAC) of recombinant proteins. However, the His-tag and IMAC technologies may cause some problems. The His-tag may interfere with the biological activity of a pro$\operatorname{tein}^{41}$, has the potential for immunogenicity and can trap metal ions during IMAC ${ }^{42}$. Furthermore, it is known that the His-tag can influence the biodistribution of engineered scaffold proteins ${ }^{43}$. Because of safety reasons and regulatory requirements especially for the production of clinical-grade proteins substantial qualities are required including removing the His-tag. For His-tag removal from proteins after their purification, as an example TEV protease can be used showing a high stringency of sequence recognition, cleavage efficiency and suitability for large-scale protein preparation ${ }^{44}$.

We therefore wanted to learn whether or not removal of the His-tag is possible in principle and how the removal of the His-tag would affect the functionality and biodistribution of a UniCAR TM. To answer this question, we modified a previously described TM directed against the TAA PSCA ${ }^{32,39}$. For that purpose, we introduced a TEV protease cleavage site between the UniCAR epitope sequence and the His-tag which allowed us to enzymatically remove the oligo-His-tag. The isolated un-tagged TM was compared with the original His-tagged TM with respect to biochemical features, functionality and biodistribution. In principle we were able to successfully remove the His-tag from the C-terminus of the recently described $\alpha$ PSCA TM ${ }^{32,39}$ by TEV digestion without major effects on its functionality and biodistribution properties. As expected, TEV mediated His-tag removal from purified TMs is a more time-consuming and cost-intensive laboratory process than the rapid one-step purification of His-tagged TMs via Nickel NTA affinity chromatography. However, His-tag removal from the $\alpha$ PSCA TM by TEV digestion resulted in sufficient amounts of un-tagged TM with high purity. Obviously, in our study the His-tag at the C-terminus of the herein used $\alpha$ PSCA TM did not affect its therapeutic functionality in combination with the UniCAR system in vitro and in vivo.

Both the $\alpha$ PSCA-His TM and $\alpha$ PSCA-w/oHis TM redirect UniCAR T cells to kill PSCA expressing tumor cells equally well. Furthermore, the activation and exhaustion status as well as the cytokine profile of UniCAR T cells redirected by both TMs reach similar levels. In this context, marginal differences between both TMs can most probably be traced to donor heterogeneity. Interestingly, both $\mathrm{CD}^{+}$and $\mathrm{CD} 8^{+}$UniCAR armed T cell subpopulations get activated in a TM-dependent and tumor-specific manner. Whilst CD69 was equally upregulated on both T cell subpopulations, the PD1 expression level on CD8 ${ }^{+}$UniCAR T cells was clearly lower than on CD4 ${ }^{+}$UniCAR $\mathrm{T}$ cells. As we transduced total $\mathrm{CD} 3^{+} \mathrm{T}$ cells with UniCAR constructs, in this study we used a mixture of $\mathrm{CD} 4^{+}$and $\mathrm{CD}^{+}$UniCAR armed T cells showing a majority of $\mathrm{CD}^{+} \mathrm{T}$ cells (approximately $70 \%$ ). However, we already published that not only $\mathrm{CD}^{+}$but also $\mathrm{CD} 4^{+}$UniCAR T cells, which were separately isolated, transduced and analysed, trigger a powerful antigen-specific tumor cell lysis with similar efficacy ${ }^{45}$. As shown in Supplementary Fig. S1(B), cytotoxicity of both UniCAR T cell subpopulations is mediated via the perforin/granzyme pathway. Furthermore, upon antigen- and TM-dependent stimulation, both UniCAR T cell subpopulations secrete pro-inflammatory cytokines GM-CSF, IFN- $\gamma$, TNF- $\alpha$, and IL-2. CD4 $4^{+}$UniCAR T cells produce significantly more TNF- $\alpha$ and IL-2 than their CD8 ${ }^{+}$counterpart (see Supplementary Fig. S1(A)). According to these results, $\mathrm{CD} 4^{+}$and $\mathrm{CD} 8^{+}$ UniCAR T cells possess effector functions within the UniCAR system in principle even separately from the other subset. A cytotoxic potential of $\mathrm{CD}^{+}$as well as $\mathrm{CD} 4^{+} \mathrm{CAR}$ armed $\mathrm{T}$ cell subsets against tumor cells was also shown by other authors ${ }^{46,47}$. However, they demonstrate differences in the effector functions of CD4 ${ }^{+}$and $\mathrm{CD} 8^{+}$ CAR subsets and improved anti-tumor effects when combining both subsets ${ }^{46,47}$.

Regarding the comparison of His-tagged and un-tagged TMs with respect to pharmacokinetic properties and biodistribution in vivo, we observed a similar biodistribution pattern for both His-tagged and un-tagged $\alpha$ PSCA TM in experimental mice. Only in the minority of analysed organs or tissues like brain, heart, liver, femur, and PSCA expressing tumors the un-tagged TM was more accumulated than the His-tagged TM. Moreover, the un-tagged TM showed a slightly better tumor to blood ratio than the His-tagged TM. In contrast, other studies showed that His-tag based labelling of imaging probes increases the hepatic uptake of affibody molecules ${ }^{48}$ and renal reabsorption of nanobodies ${ }^{49}$. However, in agreement with other authors ${ }^{43}$, the influence of the His-tag depends on the composition of the engineered scaffold protein, the His-tag position within the molecule as well as on labelling and imaging procedures.

In summary, introducing a TEV protease cleavage site into the TM allowed us to remove the His-tag and isolate a His-tag-free TM. According to our data, removal of the His-tag had little effect if any on its binding affinity and killing capability both in vitro and in vivo. We only observed a slight yet not significant difference with respect to its biodistribution. 


\section{Methods}

Cell lines. Murine 3T3, human HEK 293T, PC3-PSCA (recombinantly expressing PSCA), PC3-PSCA/PSMA (recombinantly co-expressing PSCA and PSMA), and PC3-PSCA/PSMA-luc (luciferase expressing) cell lines were gained, used and cultured as described previously $y^{30-39}$.

Isolation, cultivation and lentiviral transduction of human T cells. Primary human T cells were isolated from healthy donors, genetically modified by lentiviral transduction, sorted, and cultured as described previously ${ }^{30-36}$. For transduction of human $\mathrm{T}$ cells lentiviral vectors were used encoding only the marker protein EGFP (vector control), the UniCAR stop construct without any signalling domains or the signalling UniCAR $\mathrm{CD} 28 / \zeta$ construct containing co-stimulatory $\mathrm{CD} 28$ and activating $\mathrm{CD} 3 \zeta$ domains. All the methods using human materials were performed in accordance with relevant local regulations and guidelines. All subjects gave their written informed consent. The local ethics committee of the medical faculty Carl Gustav Carus of the university hospital Carl Gustav Carus of the TU Dresden approved the study (EK27022006).

Construction, expression and purification of TMs. Cloning, expression, purification, and functional analysis of the original His-tagged $\alpha$ PSCA-His TM was performed as described previously $y^{32,39}$.

In order to obtain the $\alpha P S C A-w / o H i s ~ T M$ a recognition site $\left(E^{-}{ }^{\prime} L Y F{ }^{\wedge} G\right)$ for the TEV protease enzyme was inserted in the $\alpha$ PSCA-His TM. The protease cleavage site locates downstream of the $\alpha$ PSCA single-chain variable fragment $(\mathrm{scFv})$ and the UniCAR epitope $\mathrm{E} 5 \mathrm{~B} 9$ sequences but upstream from the myc- and His-tag in the $\alpha$ PSCA-His TM construct. Thus, the resulting novel $\alpha$ PSCA-TEV ${ }_{R S}$-His TM construct consists of an Ig kappa signal peptide (SP), $\alpha$ PSCA scFv, E5B9, TEV recognition site $\left(\mathrm{TEV}_{\mathrm{RS}}\right)$, myc-tag, and His-tag. For cloning of the novel $\alpha$ PSCA-TEV ${ }_{\mathrm{RS}}-\mathrm{His} \mathrm{TM}$ the respective DNA fragment was ordered from Eurofins Genomics (Ebersberg, Germany). For permanent production of $\alpha \mathrm{PSCA}-\mathrm{TEV}_{\mathrm{RS}}-\mathrm{His} \mathrm{TM}, 3 \mathrm{~T} 3$ cells were transduced with the respective lentiviral vector system and $\alpha$ PSCA-TEV $\mathrm{RS}_{\mathrm{S}}$-His TMs were purified by Ni-NTA affinity chromatography from cell culture supernatants. Cloning into the vector p6NST50, transduction of 3T3 cells and TM purification were performed as described previously ${ }^{32-36}$. After purification the imidazole containing samples were dialysed overnight against 1x PBS (Biochrom). Purity and concentration of the TMs were analysed by SDS-PAGE and immunoblotting ${ }^{50-52}$.

Removal of the His-tag from the TM. In order to generate $\alpha$ PSCA-w/oHis TMs the eukaryotically produced and purified novel $\alpha$ PSCA-TEV ${ }_{R S}-$ His TM was digested with TEV protease. TEV protease reaction was performed in $1 \mathrm{x}$ cleavage buffer $(50 \mathrm{mM}$ Tris- $\mathrm{HCl} \mathrm{pH} \mathrm{8.0,0.5} \mathrm{mM} \mathrm{EDTA,} 2 \mathrm{mM} \mathrm{DTT})$ at $4^{\circ} \mathrm{C}$ for $24 \mathrm{~h}$. Prior to the cleavage reaction the concentration of the purified and dialysed $\alpha \mathrm{PSCA}-\mathrm{TEV}_{\mathrm{RS}}-\mathrm{His} \mathrm{TM}$ fraction was adjusted to a concentration of $1 \mathrm{mg} / \mathrm{ml}$ in PBS. TEV protease (Sigma-Aldrich Chemie GmbH, München, Germany) was added at a protease to target protein ratio of 1:50 (w/w). After $24 \mathrm{~h}$ incubation time, the reaction mixture was passed again through a Ni-NTA column. The flow through fraction contained the $\alpha$ PSCA-w/oHis TM. Elution fractions contained uncleaved $\alpha$ PSCA-TEV ${ }_{\text {RS }}$-His TM, the His-tagged TEV protease and the cleaved oligo-His-tag. Isolated samples were dialysed and analysed by SDS-PAGE and immunoblotting.

High-performance liquid chromatography. Size exclusion high-performance liquid chromatography (SE-HPLC) was performed to confirm the purity of the TM fractions as described previously ${ }^{31,34}$.

Flow cytometry analysis. Specific binding of His-tagged and un-tagged TMs to PSCA-positive tumor cells was assessed by flow cytometry analysis. Briefly, $2 \times 10^{5}$ of tumor cells were incubated with $25 \mathrm{ng} / \mu \mathrm{l}$ of the respective TM for $1 \mathrm{~h}$. To estimate the binding affinity to PSCA and to determine the equilibrium dissociation constant $\left(K_{D}\right)$ values of the respective TM, target cells were incubated with increasing TM concentrations ranging between $0.1 \mathrm{ng} / \mu \mathrm{l}$ and $100 \mathrm{ng} / \mu \mathrm{l}$. In order to detect specific TM binding, cells were subsequently stained with a mouse $\alpha$ E5B9 mAb directed against the UniCAR epitope E5B9 fused to the TM and finally with a PE-conjugated goat $\mathrm{F}\left(\mathrm{ab}\right.$ ')2 fragment $\alpha$-mouse IgG-PE (Beckman Coulter GmbH, Krefeld, Germany) as detection Ab. MACSQuant ${ }^{\circledR}$ Analyzer and MACSQuantify ${ }^{\circledR}$ software (Miltenyi Biotec GmbH, Bergisch Gladbach, Germany) were used to analyse stained cells. Binding curves were created based on the relative median of fluorescence intensity of stained cells and $K_{D}$ values were calculated with GraphPad Prism 7 software (GraphPad Software Inc., La Jolla, CA, USA).

Cytotoxicity assay. Chromium release assays were performed to analyse whether redirected UniCAR $\mathrm{CD} 28 / \zeta$ armed T cells can eliminate tumor cells. Therefore, ${ }^{51} \mathrm{Cr}$-labelled tumor cells were co-cultivated with UniCAR CD28/ $/$ armed T cells at an E:T ratio of 5:1 in the absence or presence of the respective TM. After $24 \mathrm{~h}$ of co-incubation, the specific tumor cell lysis was calculated as previously described ${ }^{31-36}$.

T cell activation and cytokine release. For analysis of the activation and exhaustion status as well as the cytokine release, $5 \times 10^{4}$ genetically modified $\mathrm{T}$ cells were incubated alone or together with $1 \times 10^{4}$ target cells in the absence or presence of $25 \mathrm{nM}$ of corresponding TM in 96-well plates in triplicates. After $24 \mathrm{~h}$ of co-cultivation, triplicates of cell-free supernatants were harvested and pooled to determine cytokine concentrations with the MACSPlex Cytokine 12 kit (Miltenyi Biotec $\mathrm{GmbH}$ ) as described previously ${ }^{31,32}$. In parallel, triplicates of co-cultured T cells were pooled and were stained with $\alpha$ CD69-APC, $\alpha$ PD1-PE, $\alpha$ CD4-PE-Vio770, and $\alpha \mathrm{CD} 8$-VioBlue $\mathrm{mAbs}$ (Miltenyi Biotec $\mathrm{GmbH}$ ) and analysed by flow cytometry.

Tumor xenograft model and optical imaging. For in vivo functionality test of both $\alpha$ PSCA TMs in combination with the UniCAR system we used a tumor xenograft model in immunodeficient mice as described previousl $y^{30-36}$. Therefore five weeks old male Rj:NMRI-Foxn $1^{\text {nu/nu }}$ mice (Janvier Labs, St. Berthevin, France) were divided in four groups each containing five animals. In all mice of the first control group only PC3-PSCA/ 
PSMA-luc tumor cells expressing luciferase $\left(0.5 \times 10^{6}\right)$ were subcutaneously injected into the right flank. Animals

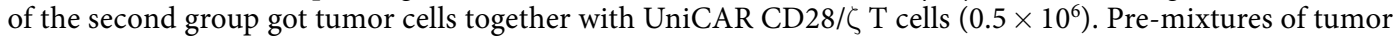
cells, UniCAR CD28/ $\zeta$ T cells and $10 \mu \mathrm{g}$ of $\alpha$ PSCA-His TM or $\alpha$ PSCA-w/oHis TM were injected into animals of the treated groups. At day zero and the following three days, bioluminescence signals were acquired by optical imaging of anesthetised mice after injection of D-luciferin potassium salt. Optical imaging was performed as described previously ${ }^{34}$. All animal studies were approved by the Landesdirektion Dresden (24-9165.40-4. 24.9168.21-4/2004-1) and performed at the Helmholtz-Zentrum Dresden-Rossendorf (HZDR) in accordance with the guidelines of German Regulations for Animal Welfare.

NODAGA conjugation and radiolabelling of the TMs. To visualise the in vivo binding of the respective $\mathrm{TM}$ at the tumor site and to compare the biodistribution and kinetics of both TMs in the Rj:NMRI-Foxn $1^{\mathrm{nu} / \mathrm{nu}}$ mouse tumor model, the TMs were conjugated with NODAGA which is a chelator for radiometals like ${ }^{68} \mathrm{Ga}^{3+}$ or ${ }^{64} \mathrm{Cu}^{2+}$. As already published ${ }^{31,33-35,53}$ the NODAGA conjugation was performed in $0.1 \mathrm{M}$ borate buffer $\mathrm{pH} 9.00$ with approximately $20 \mathrm{nmol} \mathrm{TM}$ and with a surplus 40 times higher of p-SCN-NODAGA over $18 \mathrm{~h}$ at $25^{\circ} \mathrm{C}$. The TMs were purified by three times spin-filtration (Amicon Ultra-4, 10,000 MWCO) with $2 \mathrm{ml}$ DPBS. The resulting proteins were analysed by MALDI-TOF that showed a mean value of two molecules NODAGA per molecule of TM. For radiolabelling the ${ }^{64} \mathrm{Cu}^{2+}$ solution was adjusted to $\mathrm{pH} 5.5$ with $2 \mathrm{~mol} / \mathrm{l} \mathrm{NH}_{4} \mathrm{OAc}$ and mixed with 1.6 nmol NODAGA-TM $(50 \mu \mathrm{g})$ and incubated at $37^{\circ} \mathrm{C}$ for $30 \mathrm{~min}$. The samples were two times spin-filtrated $(10,000$ $\mathrm{MWCO}$ ) with $2 \mathrm{ml}$ DPBS containing $2 \mathrm{mM}$ EDTA. The resulting radiochemical purity was analysed by ITL with the same buffer.

In vivo biodistribution of radiolabelled TMs. Rj:NMRI Foxn $1^{\text {nu/nu }}$ mice bearing a subcutaneous PC3-PSCA tumor $(0.53 \mathrm{~g} \pm 0.25 \mathrm{~g})$ on the right hind leg and with a body weight of $26.3 \mathrm{~g} \pm 1.3 \mathrm{~g}$ were intravenously injected with $0.5 \mathrm{MBq}$ of ${ }^{64} \mathrm{Cu}$-labelled TMs. $120 \mathrm{~min}$ after injection, the activity of different collected tissues and organs were analysed. The activity amount was expressed as percentage of injected dose (\% ID) and the activity concentration was calculated as standardised uptake values (SUV). The method was described in more detail previously $31,33-35,53,54$.

In vivo small animal positron emission tomography (PET). The procedures are described in detail elsewhere ${ }^{31,33-35,53,54}$. Radiolabelled TMs were intravenously injected in mice. To demonstrate the activity uptake, images were added with midframe times of $1,5,30,60,90$, and $120 \mathrm{~min}$ and presented as maximum intensity projections (MIP). SUV were calculated and the kinetic data were generated as ${ }^{64} \mathrm{Cu}$-activity concentration time curves (mean \pm SEM of four animals). The tumor to blood and tumor to muscle ratios were calculated as tumor to background (TBR) ratio.

Statistical analysis. Statistical analysis was done as previously described ${ }^{45}$.

\section{Data Availability}

Data confirming the results of this study are presented in the manuscript and are available from the corresponding author upon reasonable request.

\section{References}

1. Gross, G., Waks, T. \& Eshhar, Z. Expression of immunoglobulin-T-cell receptor chimeric molecules as functional receptors with antibody-type specificity. Proc. Natl. Acad. Sci. USA 86, 10024-10028 (1989).

2. Maher, J., Brentjens, R. J., Gunset, G., Rivière, I. \& Sadelain, M. Human T-lymphocyte cytotoxicity and proliferation directed by a single chimeric TCRzeta /CD28 receptor. Nat Biotechnol. 20, 70-75 (2002).

3. Sadelain, M., Brentjens, R. \& Rivière, I. The promise and potential pitfalls of chimeric antigen receptors. Curr Opin Immunol. 21, 215-223 (2009)

4. Cartellieri, M. et al. Chimeric antigen receptor-engineered T cells for immunotherapy of cancer. J Biomed Biotechnol. 2010, 956304 (2010).

5. Brentjens, R. J. et al. CD19-targeted T cells rapidly induce molecular remissions in adults with chemotherapy-refractory acute lymphoblastic leukemia. Sci Transl Med. 5, 177ra38 (2013).

6. Porter, D. L., Levine, B. L., Kalos, M., Bagg, A. \& June, C. H. Chimeric antigen receptor-modified T cells in chronic lymphoid leukemia. N Eng J Med. 365, 725-733 (2011).

7. Porter, D. L. et al. Chimeric antigen receptor T cells persist and induce sustained remissions in relapsed refractory chronic lymphocytic leukemia. Sci Transl Med. 7, 303ra139 (2015).

8. Kalos, M. et al. T cells with chimeric antigen receptors have potent antitumor effects and can establish memory in patients with advanced leukemia. Sci Transl Med. 3, 95ra73 (2011).

9. Kochenderfer, J. N. et al. B-cell depletion and remissions of malignancy along with cytokine-associated toxicity in a clinical trial of anti-CD19 chimeric-antigen-receptor-transduced T cells. Blood 119, 2709-2720 (2012).

10. Kochenderfer, J. N. et al. Chemotherapy-refractory diffuse large B-cell lymphoma and indolent B-cell malignancies can be effectively treated with autologous T cells expressing an anti-CD19 chimeric antigen receptor. J clin Oncol. 33, 540-549 (2015).

11. Grupp, S. A. et al. Chimeric antigen receptor-modified T cells for acute lymphoid leukemia. N Eng J Med. 368, 1509-1518 (2013).

12. Davila, M. L. et al. Efficacy and toxicity management of 19-28z CAR T cell therapy in B cell acute lymphoblastic leukemia. Sci Transl Med. 6, 224ra25 (2014).

13. Maude, S. L. et al. Chimeric antigen receptor T cells for sustained remissions in leukemia. N Eng J Med. 371, 1507-1517 (2014).

14. Garfall, A. L. et al. Chimeric Antigen Receptor T Cells against CD19 for Multiple Myeloma. N Eng J Med. 373, 1040-1047 (2015).

15. Lee, D. W. et al. T cells expressing CD19 chimeric antigen receptors for acute lymphoblastic leukaemia in children and young adults: a phase 1 dose-escalation trial. Lancet 385, 517-528 (2015).

16. Brudno, N. J. \& Kochenderfer, J. N. Toxicities of chimeric antigen receptor T cells: recognition and management. Blood 127, $3321-3330$ (2016).

17. Curran, K. J., Pegram, H. J. \& Brentjens, R. J. Chimeric antigen receptors for T cell immunotherapy: current understanding and future directions. J Gene Med. 14, 405-415 (2012).

18. Hoyos, V. et al. Engineering CD19-specific T lymphocytes with interleukin-15 and a suicide gene to enhance their anti-lymphoma / leukemia effects and safety. Leukemia 24, 1160-1170 (2010). 
19. Fedorov, V. D., Themeli, M. \& Sadelain, M. PD-1- and CTLA-4-based inhibitory chimeric antigen receptors (iCARs) divert off-target immunotherapy responses. Sci. Transl. Med. 5, 215 ra172 (2013).

20. Eyquem, J. et al. Targeting a CAR to the TRAC locus with CRISPR/Cas9 enhances tumour rejection. Nature 543, 113-117 (2017).

21. Kloss, C. C., Condomines, M., Cartellieri, M., Bachmann, M. \& Sadelain, M. Combinatorial antigen recognition with balanced signaling promotes selective tumor eradication by engineered T cells. Nat Biotechnol. 31, 71-75 (2013).

22. Urbanska, K. et al. A universal strategy for adoptive immunotherapy of cancer through use of a novel T-cell antigen receptor. Cancer Res. 72, 1844-1852 (2012).

23. Liu, K. et al. Retargeted human avidin-CAR T cells for adoptive immunotherapy of EGFRvIII expressing gliomas and their evaluation via optical imaging. Oncotarget 6, 23735-23747 (2015).

24. Dale, G. L., Gaddy, P. \& Pikul, F. J. Antibodies against biotinylated proteins are present in normal human serum. J Lab Clin Med. 123, 365-371 (1994)

25. Koristka, S. et al. Flexible Antigen-Specific Redirection of Human Regulatory T Cells Via a Novel Universal Chimeric Antigen Receptor System. Blood 124, 3494 (2014).

26. Cao, Y. et al. Design of Switchable Chimeric Antigen Receptor T Cells Targeting Breast Cancer. Angew Chem Int Ed Engl. 55, 7520-7524 (2016).

27. Ma, J. S. et al. Versatile strategy for controlling the specificity and activity of engineered T cells. Proc Natl Acad Sci USA 113, E450-458 (2016).

28. Rodgers, D. T. et al. Switch-mediated activation and retargeting of CAR-T cells for B-cell malignancies. Proc Natl Acad Sci USA 113, E459-468 (2016).

29. Carmo-Fonseca, M. et al. Identification of La ribonucleoproteins as a component of interchromatin granules. Exp Cell Res. 185, 73-85 (1989).

30. Cartellieri, M. et al. Switching CAR T cells on and off: a novel modular platform for retargeting of T cells to AML blasts. Blood Cancer J. 6, e458 (2016).

31. Albert, S. et al. A novel nanobody-based target module for retargeting of T lymphocytes to EGFR-expressing cancer cells via the modular UniCAR platform. Oncoimmunol. 6, e1287246, https://doi.org/10.1080/2162402X.2017.1287246 (2017).

32. Feldmann, A. et al. Retargeting of T lymphocytes to PSCA- or PSMA positive prostate cancer cells using the novel modular chimeric antigen receptor platform technology “UniCAR”. Oncotarget 8, 31368-31385 (2017).

33. Bachmann, D. et al. Retargeting of UniCAR T cells with an in vivo synthesized target module directed against CD19 positive tumor cells. Oncotarget 9, 7487-7500 (2017)

34. Mitwasi, N. et al. Development of novel target modules for retargeting of UniCAR T cells to GD2 positive tumor cells. Oncotarget 8, 108584-108603 (2017).

35. Albert, S. et al. From mono- to bivalent: improving theranostic properties of target modules for redirection of UniCAR T cells against EGFR-expressing tumor cells in vitro and in vivo. Oncotarget 9, 25597-25616 (2018).

36. Loureiro, L. R. et al. Development of a novel target module redirecting UniCAR T cells to Sialyl Tn-expressing tumor cells. Blood Cancer J. 8, 81 (2018).

37. Feldmann, A. et al. Retargeting of $\mathrm{T}$ cells to prostate stem cell antigen expressing tumor cells: comparison of different antibody formats. Prostate 71, 998-1011 (2011).

38. Feldmann, A. et al. Novel humanized and highly efficient bispecific antibodies mediate killing of prostate stem cell antigenexpressing tumor cells by $\mathrm{CD} 8^{+}$and $\mathrm{CD} 4^{+} \mathrm{T}$ cells. J Immunol. 189, 3249-3259 (2012).

39. Arndt, C. et al. Simultaneous targeting of prostate stem cell antigen and prostate-specific membrane antigen improves the killing of prostate cancer cells using a novel modular T cell-retargeting system. Prostate 74, 1335-1346 (2014).

40. Casey, J. L. et al. Purification of bacterially expressed single chain Fv antibodies for clinical applications using metal chelate chromatography. J. Immunol. Methods 179, 105-116 (1995).

41. Lee, J. et al. The catalytic activity of a recombinant single chain variable fragment nucleic acid-hydrolysing antibody varies with fusion tag and expression host. Arch Biochem Biophys. 633, 110-117 (2017).

42. Gaberc-Porekar, V. \& Menart, V. Perspectives of immobilized-metal affinity chromatography. J Biochem Biophys Methods 49, 335-360 (2001).

43. Lindbo, S. et al. Influence of Histidine-Containing Tags on the Biodistribution of ADAPT Scaffold Proteins. Bioconjug Chem. 27, 716-726 (2016)

44. Raran-Kurussi, S., Cherry, S., Zhang, D. \& Waugh, D. S. Removal of Affinity Tags with TEV Protease. Methods Mol Biol. 1586, 221-230 (2017).

45. Koristka, S. et al. Engrafting human regulatory T cells with a flexible modular chimeric antigen receptor technology. J Autoimmun. 90, 116-131 (2018)

46. Wang, D. et al. Glioblastoma-targeted CD4+ CAR T cells mediate superior antitumor activity. JCI Insight 3, 99048 (2018).

47. Sommermeyer, D. et al. Chimeric antigen receptor-modified T cells derived from defined CD8+ and CD4+ subsets confer superior antitumor reactivity in vivo. Leukemia 30, 492-500 (2016).

48. Ahlgren, S. et al. Targeting of HER2-expressing tumors with a site-specifically $99 \mathrm{mTc}$-labeled recombinant affibody molecule, ZHER2:2395, with C-terminally engineered cysteine. J. Nucl. Med. 50, 781-789 (2009).

49. D’Huyvetter, M. et al. Targeted radionuclide therapy with A 177Lu-labeled anti-HER2 nanobody. Theranostics 4, 708-720 (2014).

50. Arndt, C. et al. Costimulation improves the killing capability of T cells redirected to tumor cells expressing low levels of CD33: description of a novel modular targeting system. Leukemia 28, 59-69 (2014).

51. Arndt, C. et al. Redirection of T cells with a first fully humanized bispecific CD33-CD3 antibody efficiently eliminates AML blasts without harming hematopoietic stem cells. Leukemia 27, 964-967 (2013).

52. Koristka, S. et al. Retargeting of regulatory T cells to surface-inducible autoantigen La/SS-B. J Autoimmun. 42, 105-116 (2013).

53. Licciardello, N. et al. Biodistribution studies of ultrasmall silicon nanoparticles and carbon dots in experimental rats and tumor mice. Nanoscale 10, 9880-9891 (2018).

54. Bergmann, R. et al. Synthesis and radiopharmacological evaluation of ${ }^{64} \mathrm{Cu}$-labeled bombesin analogs featuring a bis $(2$ pyridylmethyl)-1,4,7-triazacyclononane chelator. Eur J Med Chem. 70, 434-46 (2013).

\section{Acknowledgements}

We thank Ulrike Gesche, Christian Jentschel and Martin Walther who prepared the ${ }^{64} \mathrm{Cu}$-isotope solutions. For technical assistance we thank Regina Herrlich supporting the animal experiments, Andrea Suhr preparing the modification and radiolabelling as well as Julia Lagler supporting the in vitro experiments.

\section{Author Contributions}

J.J., A.F., R.B., N.B., S.K., A.K., E.P., J.A.S. and C.A. planed, performed and analysed the experiments. J.J., A.F. and R.B. arranged the figures of the manuscript. The manuscript was written by J.J., A.F., R.B. and M.B. All authors reviewed and approved the manuscript. 


\section{Additional Information}

Supplementary information accompanies this paper at https://doi.org/10.1038/s41598-019-47044-4.

Competing Interests: M.B. has invented the UniCAR system and holds patents related to the UniCAR system. $\mathrm{He}$ is co-founder and shareholder of the company GEMoaB Monoclonals $\mathrm{GmbH}$ which owns the IP related to the UniCAR system. M.B. declares no non-financial competing interests. All the other authors declare no financial and no non-financial competing interests.

Publisher's note: Springer Nature remains neutral with regard to jurisdictional claims in published maps and institutional affiliations.

(c) (i) Open Access This article is licensed under a Creative Commons Attribution 4.0 International License, which permits use, sharing, adaptation, distribution and reproduction in any medium or format, as long as you give appropriate credit to the original author(s) and the source, provide a link to the Creative Commons license, and indicate if changes were made. The images or other third party material in this article are included in the article's Creative Commons license, unless indicated otherwise in a credit line to the material. If material is not included in the article's Creative Commons license and your intended use is not permitted by statutory regulation or exceeds the permitted use, you will need to obtain permission directly from the copyright holder. To view a copy of this license, visit http://creativecommons.org/licenses/by/4.0/.

(c) The Author(s) 2019 